\title{
Molecular mechanisms underlying memory consolidation of taste information in the cortex
}

\author{
Shunit Gal-Ben-Ari ${ }^{1,2}$ and Kobi Rosenblum ${ }^{1,2}$ * \\ ${ }^{1}$ Department of Neurobiology, University of Haifa, Haifa, Israel \\ ${ }^{2}$ Center for Gene Manipulation in the Brain, University of Haifa, Haifa, Israel
}

\section{Edited by:}

Riccardo Brambilla, San Raffaele

Scientific Institute and University, Italy

Reviewed by:

Riccardo Brambilla, San Raffaele

Scientific Institute and University, Italy

Clive R. Bramham, University of

Bergen, Norway

*Correspondence:

Kobi Rosenblum, Department of

Neurobiology and Ethology, Center for Gene Manipulation in the Brain,

University of Haifa, Mt Carmel, Haifa 31905, Israel.

e-mail: kobir@psy.haifa.ac.il
The senses of taste and odor are both chemical senses. However, whereas an organism can detect an odor at a relatively long distance from its source, taste serves as the ultimate proximate gatekeeper of food intake: it helps in avoiding poisons and consuming beneficial substances. The automatic reaction to a given taste has been developed during evolution and is well adapted to conditions that may occur with high probability during the lifetime of an organism. However, in addition to this automatic reaction, animals can learn and remember tastes, together with their positive or negative values, with high precision and in light of minimal experience. This ability of mammalians to learn and remember tastes has been studied extensively in rodents through application of reasonably simple and well defined behavioral paradigms. The learning process follows a temporal continuum similar to those of other memories: acquisition, consolidation, retrieval, relearning, and reconsolidation. Moreover, inhibiting protein synthesis in the gustatory cortex (GC) specifically affects the consolidation phase of taste memory, i.e., the transformation of short- to long-term memory, in keeping with the general biochemical definition of memory consolidation. This review aims to present a general background of taste learning, and to focus on recent findings regarding the molecular mechanisms underlying taste-memory consolidation in the GC. Specifically, the roles of neurotransmitters, neuromodulators, immediate early genes, and translation regulation are addressed.

Keywords: taste learning, consolidation, gustatory cortex, insular cortex, MAPK, ERK, translation regulation, conditioned taste aversion

\section{INTRODUCTION}

Intake of food and avoidance of poison are crucial to an organism's survival in a dynamic environment. The process of deciding whether food is "safe" or "hazardous" relies heavily on the gustatory and somatosensory systems, which are involved in evaluating diverse properties of putative foods, such as: chemosensory, e.g., modality, intensity; orosensory, e.g., texture, temperature, pungency; and gratification capacity (Rosenblum, 2008; Carleton et al., 2010).

The sense of taste differs from the other senses in two major characteristics: (1) Each taste input has dual labeling, one related to its physical (texture and temperature) and chemical features, and the other to its hedonic value and safety; (2) Deciding on the safety aspects of a novel sensation, such as the taste of an unfamiliar food, involves a different temporal scale from other senses: taste association with unconditioned stimulus (US) takes $1-12 \mathrm{~h}$ (Bures et al., 1998; Merhav and Rosenblum, 2008), compared with a few seconds for responses to other sensations.

Two main strategies are used by various species, including humans, in responding to various tastes: genetic programming, i.e., affinity to sweet tastes, aversion to bitter ones, and complex learning mechanisms that involve several forebrain structures (Rosenblum, 2008). Modification of the basic genetic programming and memories of new tastes and their values are expected to be mediated, at least in part, by the gustatory cortex (GC;
Yamamoto et al., 1984, 1985; Rosenblum, 2008; Doron and Rosenblum, 2010), which is defined according to its cytoarchitectonic boundaries as the dysgranular part of the insular cortex (IC; Burwell, 2001). This is in line with its unique anatomical connections (Figure 1), through which it receives multimodal sensory inputs, including visceral, gustatory, and somatosensory information from sensory thalamic nuclei (Fujita et al., 2010). However, other brain regions, such as the basolateral amygdala (Bla) and dorsal hippocampus, have been shown to be activated during novel taste processing (Yefet et al., 2006; Doron and Rosenblum, 2010), and also to be necessary for safe taste-memory consolidation (De la Cruz et al., 2008). Most of the studies of the molecular mechanisms underlying taste memory were performed in mice and rats, therefore, the present review will focus on these studies.

Taste recognition on the receptor level, as well as taste reactivity, as defined genetically, are beyond the scope of this review; they have been extensively covered elsewhere (Frank et al., 2008; Carleton et al., 2010). The first objective of this review is to describe taste-related behavior paradigms, in order to elucidate the molecular and cellular mechanisms underlying learning and memory. We then provide a detailed analysis of the currently known molecular and cellular mechanisms of taste learning in the GC, which resides in the IC. We aim to focus mainly on studies during the last decade; previous studies have been reviewed elsewhere (Bures et al., 1998; Rosenblum, 2008). 


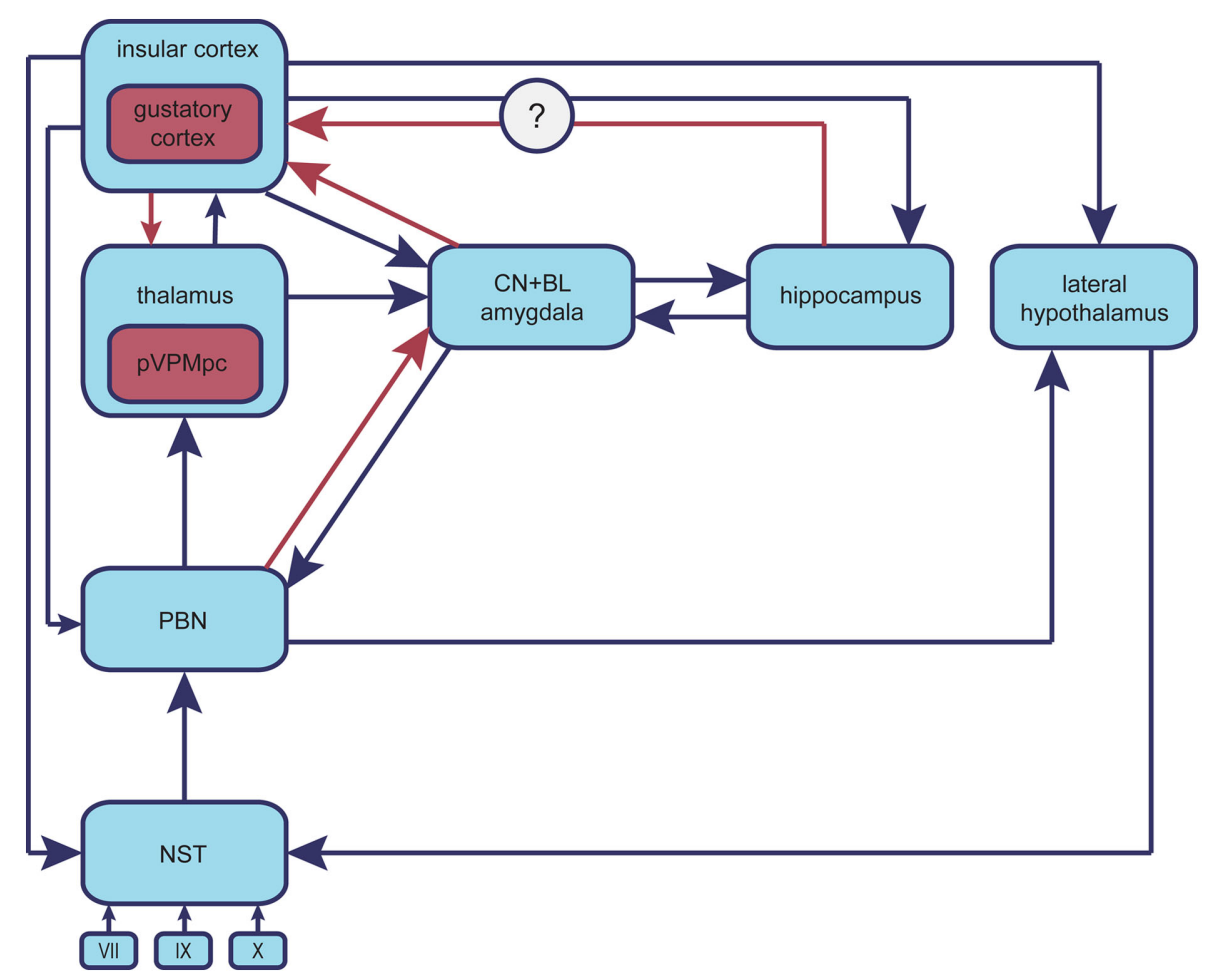

FIGURE 1 | Neuroanatomy of the taste system. Chemical stimuli originating in alimentary sources, upon reaching the oral cavity initiate the processing of gustatory information (CN, central nucleus; BLA, basolateral amygdala; NST, nucleus of solitary tract; PBN, parabrachial nucleus; pVPMpc, parvocellular part of the ventralis postmedial thalamic nucleus of the thalamus; GC, gustatory cortex). Taste cells, which are broadly tuned to the diverse taste modalities, are innervated by cranial nerves VII, IX, X, which project to the primary gustatory nucleus in the brainstem (NST). The NST sends information to three different systems: the reflex system, the lemniscal system, and the visceral-limbic system. The reflex system comprises medullary and reticular-formation neurons, which innervate the cranial motor nuclei. The lemniscal system consists of projections of the gustatory portion of the NST to the secondary nucleus situated in the dorsal pons (PBN); this, in turn, sends axons to the pVPMpc, which ultimately relays gustatory information to the anterior part of the insular cortex (GC). The visceral-limbic system refers to a collateral network of connections to the hypothalamus and limbic areas in the forebrain, which comprises the central gustatory pathway. The PBN is connected to the amygdala, the hypothalamus, and the bed-nucleus of the stria terminalis. All limbic gustatory targets are interconnected with each other as well as with the PBN and the GC.

\section{BEHAVIOR PARADIGMS FOR THE MEASUREMENT OF TASTE} LEARNING, MEMORY, AND CONSOLIDATION

The molecular mechanisms underlying learning and memory are the subject of ongoing research. Although learning and memory are considered to be two different processes, they involve a continuum of events. Following a discrete event, physical changes underlying memory encoding and processing of the information to be stored takes place. Ethologically, this is described as the acquisition phase; it involves creation of an internal representation of the novel information. This representation remains labile for some time, while the process of consolidation takes place. During this process the new memory becomes increasingly resistant to disruption (Alberini, 2011), which can involve several types of intervention: behavioral (e.g., Merhav et al., 2006), pharmacological (e.g., Rosenblum et al., 1993), or others (Bures et al., 1998). It has been shown that the consolidation of new memory can be disrupted by many events, including: blocking synthesis of new RNA or protein, e.g., by actimomycin D or anisomycin, respectively; disruption of the expression or function of specific proteins; new learning; brain cooling; seizure, e.g., through electric shock; brain trauma; and regional brain lesions (Alberini, 2011). During the consolidation phase, the memory is transformed from shortterm memory (STM), which may last from minutes to hours, to long-term memory (LTM), which may last from days to a lifetime (McGaugh, 2000; Kandel, 2001; Dudai, 2004). The time frame of the "consolidation phase" can vary within a given learning paradigm; it depends on the manipulation, and may reflect several different cellular and molecular processes (Figure 2). One may ask whether the difference between consolidation and maintenance of memories is an artificial one, since the processes can also be regarded as continuous processing of the information by varied molecular and cellular mechanisms within a certain cortical area. They can also be considered in terms of temporally differential involvement of several brain structures.

The next phase of memory processing is use or retrieval of the memory, during which it is susceptible to further changes, associated with a process of reconsolidation, which mediates its restabilization. The stability of a memory depends on its age: new memories are sensitive to post-reactivation disruption, but older ones are more resistant (Alberini, 2011).

Ethologically, learning is usually classified into non-associative (habituation and sensitization), associative (relationships between 


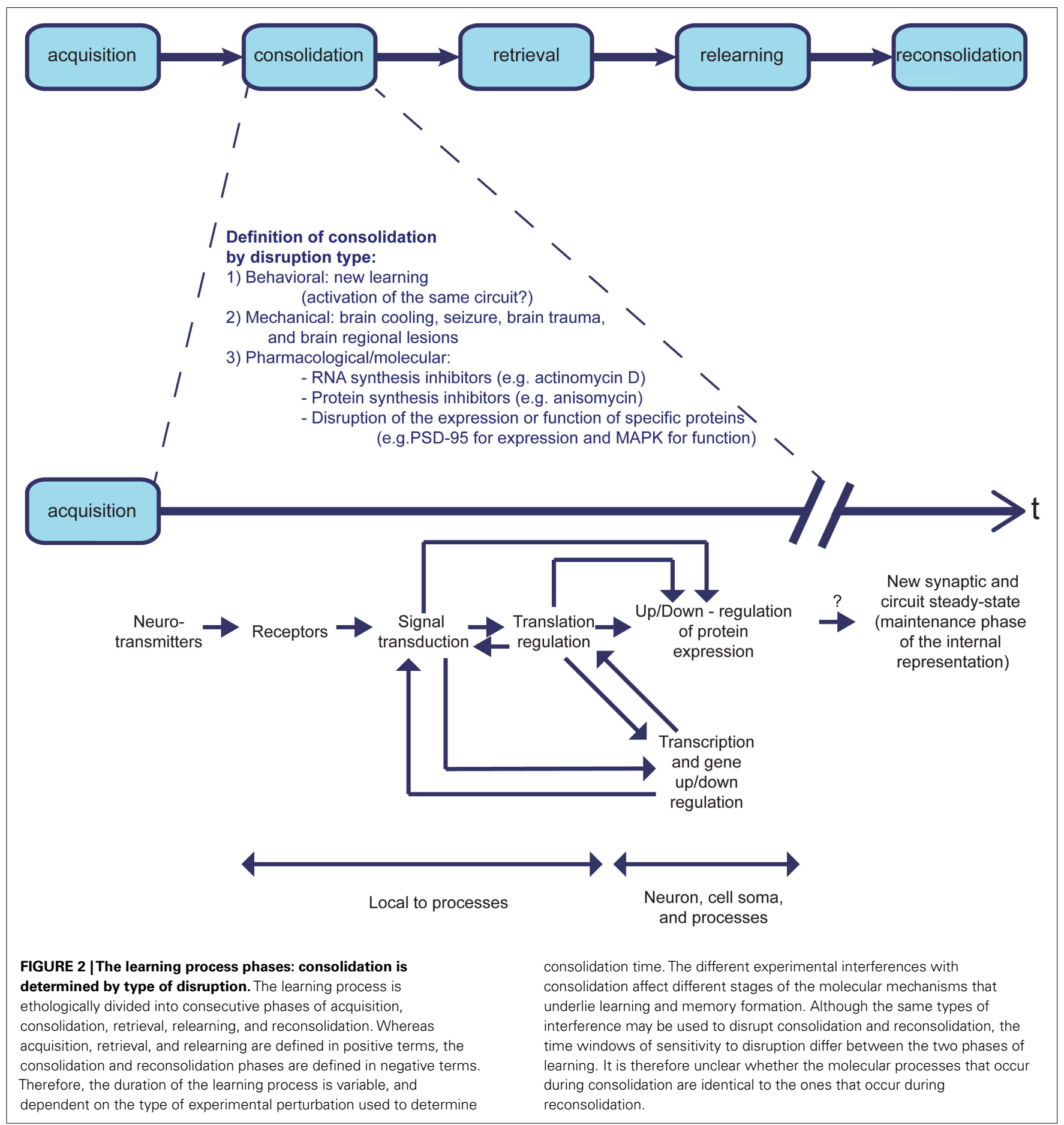

amounts and events), and incidental learning (learning in the absence of explicit external reinforcement; Gibb et al., 2006; Morris, 2006; Miranda et al., 2008; Rosenblum, 2008; Lindquist et al., 2009). Over the years, different behavioral paradigms have been developed in order to study the different types of learning, and also to address the abovementioned temporal phases of memory formation.

One of the most widespread taste-learning paradigms is the negative-learning, conditioned taste aversion (CTA) paradigm, in which an association is formed between a novel taste (serving as a conditioned stimulus - CS) and malaise (serving as an unconditioned stimulus - US), resulting in the animal's subsequent avoidance of the novel food associated with delayed food poisoning (conditioned response-CR; Garcia et al., 1955; Bures et al., 1998). The acquisition of CTA is subserved by specific brain regions, including the IC and the amygdala, although their precise role in CTA is still unclear (Yamamoto et al., 1994; Lamprecht and Dudai, 1996), and it has been demonstrated that induction of neurotoxic 
lesions in the IC disrupts acquisition of CTA (Roman et al., 2006; Roman and Reilly, 2007). Similarly, lesions of the basolateral region (Bla), but not of the central nucleus of the amygdala, selectively disrupt CTA performance (Nachman and Ashe, 1974; Morris et al., 1999; St Andre and Reilly, 2007). CTA is commonly used when a hippocampus-independent form of learning is addressed.

A widely used paradigm of positive-learning is latent inhibition of CTA (LI-CTA), in which an animal learns that a novel food is safe, and displays less aversion following CTA than animals subjected to CTA alone (Bures et al., 1998). The LI-CTA paradigm involves presentation of a novel taste to an animal prior to CTA. Since this early experience elicits no negative consequences, the animal displays reduced aversion to the same taste following CTA (Rosenblum et al., 1993). This modulation of behavior can be attributed either to reduced strength of the association at the time of the CTA or to competition during the retrieval phase (Lubow, 1989). LI-CTA is a form of incidental learning that depends on both the quantity of novel taste consumed and the functionality of the GC (Rosenblum et al., 1993; Merhav and Rosenblum, 2008).

Under certain conditions, CTA can be extinguished (Berman et al., 2003). Extinction reflects a decrease in the CR in the absence of reinforcement of a conditioned stimulus. Behavioral evidence indicates that extinction involves an inhibitory learning mechanism in which the extinguished CR reappears following presentation of an unconditioned stimulus. However, studies have shown that the memory was not erased in rats and humans (Lin et al., 2010).

Taste learning and CTA have several advantages as paradigms for studying molecular mechanisms underlying learning and memory. These include: one-trial learning; strong incidental learning; clear and short learning time; minimal behavioral manipulation, since the animals can learn in their home cage with very little interference from other modalities; the sensory input is clearly defined, and therefore can be quantified in molecular terms; clearly defined cortical area(s) subserve the learning; and high reproducibility (Bures et al., 1998; Rosenblum, 2008).

\section{LONG-TERM POTENTIATION IN THE INSULAR CORTEX}

The most studied form of neuronal adaptations is Hebbian plasticity, which includes long-term potentiation (LTP), and its reciprocal, long-term depression (LTD; Collingridge et al., 2004; Malenka and Bear, 2004; Feldman, 2009; Pozo and Goda, 2010). Hallmark features of LTP are that synaptic changes are associative, rapidly induced, and input specific. These features facilitate reinforcement of active synaptic connections with a given set of sensory stimuli, thus eliciting an activity-induced increase in synaptic efficacy, which is widely expressed in several pleo- and neocortical areas. Taken together, these characteristics render LTP an attractive model for a cellular basis for learning and memory (Bliss and Collingridge, 1993; Neves et al., 2008; Rosenblum, 2008; Sjostrom et al., 2008).

Long-term potentiation has been described in several brain areas, including the hippocampus and the cortex, and in conjunction with taste learning, (Escobar et al., 1998, 2002; Ramirez-Lugo et al., 2003; Chen et al., 2006; Alme et al., 2007; Bramham, 2007; McGeachie et al., 2011; Rodriguez-Duran et al., 2011). It was demonstrated that tetanic stimulation of the basolateral amygdaloid nucleus (Bla) induced N-methyl-Daspartate (NMDA)-dependent but metabotropic glutamate receptor (mGluR)-independent LTP in the IC (Escobar et al., 1998, 2002; Jones et al., 1999). It is important to note that IC-LTP and CTA both involve similar molecular mechanisms in the IC, such as NMDA receptor (NMDAR) dependence, activation of ERK1/2, and induction of immediate early genes (IEGs), including Zif268, Fos, Arc, and Homer (Jones et al., 1999; Rodriguez-Duran et al., 2011).

However, it remains to be more robustly proven that LTP-like mechanisms in the IC subserve taste learning. It was shown that induction of LTP in the Bla-IC projection prior to CTA enhanced CTA retention (Escobar and Bermudez-Rattoni, 2000). In addition, it was shown that on the one hand, intracortical microinfusion of brain-derived neurotrophic factor (BDNF) induced LTP in the Bla-IC projection of adult rats (Escobar et al., 2003), and on the other hand, that intracortical microinfusion of BDNF prior to CTA training enhanced retention of this task (Castillo et al., 2006).

In a follow-up study, Rodriguez-Duran et al. (2011) have shown that when the paradigm was reversed, i.e., CTA was performed prior to LTP induction in the Bla-IC projection, CTA training prevented the subsequent induction of LTP in the Bla-IC projection for at least $120 \mathrm{~h}$ after CTA training. In addition, they showed that CTA training produced a persistent change in the possibility of inducing subsequent LTP in the Bla-IC projection in a protein-synthesis-dependent manner, and inferred that changes in the possibility of inducing subsequent synaptic plasticity contributed to the formation and persistence of aversive memories (Rodriguez-Duran et al., 2011).

Long-term potentiation consists of two phases on the molecular level: induction, which triggers potentiation, and maintenance, which sustains the potentiation over time. Many molecules have been shown to be involved in the induction phase of LTP, but very few have been implicated in the maintenance phase. Since the working hypothesis is that LTP is the cellular mechanism underlying LTM storage, the molecular mechanisms relevant to the maintenance phase are highly important. To the best of our knowledge, to date, only a single molecule, protein kinase $\mathrm{M} \zeta(\mathrm{PKM} \zeta)$, has been found to be necessary for maintenance in both the hippocampus (spatial learning) and the IC (CTA): local injection of ZIP, a PKM $\zeta$ selective inhibitor, into the hippocampus resulted in reversal of LTP maintenance in vivo and loss of 1 day old spatial memory (Pastalkova et al., 2006). Similarly, its injection into the GC resulted in reversal of long-term CTA memory in a dosedependent manner, whereas other serine/threonine protein kinase inhibitors are capable of interference with long-term memory formation, but are ineffective once the memory has been established (Shema et al., 2009, 2011).

Protein kinase $\mathrm{M} \zeta$ is the brain-specific atypical protein kinase $\mathrm{C}$ (PKC) isoform, which unlike full-length $\mathrm{PKC}$ isoforms, is a cleaved form comprising the independent catalytic domain of $\mathrm{PKC} \zeta$, and is a second messenger-independent kinase. $\mathrm{PKM} \zeta$ is constitutively active in sustaining LTP maintenance, and studies have shown that it mediates synaptic potentiation specifically during the late phase of LTP. LTP induction increases new PKM $\zeta$ synthesis, leading to enhanced synaptic transmission. The mechanism underlying L-LTP and spatial memory maintenance by PKM $\zeta$ is thought 
to involve AMPA receptor phosphorylation and trafficking, with subsequent changes in the amplitude of excitatory postsynaptic potential (EPSP) concomitant with dendritic translation regulated by PKM $\zeta$ phosphorylation (and inhibition) of Pin1 (Sacktor, 2008; Vlachos et al., 2008; Navakkode et al., 2010; Parvez et al., 2010; von Kraus et al., 2010; Westmark et al., 2010; Mei et al., 2011; Sajikumar and Korte, 2011).

\section{NEUROTRANSMITTERS IN THE GUSTATORY CORTEX INVOLVED IN TASTE LEARNING}

The working hypothesis is that an organism relies on its sensory system, specifically, in the present context, the sense of taste, to create an internal representation of a given physical or chemical stimulus. The sensory information is converted into neuronal activity that subserves the various phases of learning, i.e., acquisition, consolidation, and retrieval. Information regarding physical/chemical properties and the significance of a given taste reaches the GC via several different neurotransmitters, and elicits the release of several neurotransmitter systems in the GC, where relevant receptors are expressed as well. Several molecular changes in the GC have been found to be correlated with novel taste learning at various time points after exposure to a novel taste. The molecules involved include acetylcholine (ACh), dopamine, noradrenaline, gamma-aminobutyric acid (GABA), glutamate, and various neuropeptides (Figure 3; Rosenblum et al., 1995, 1996, 1997; Berman et al., 2000; Belelovsky et al., 2005, 2009; Koh and Bernstein, 2005; Merhav et al., 2006; Banko et al., 2007; CostaMattioli et al., 2007; Elkobi et al., 2008; Merhav and Rosenblum, 2008; Barki-Harrington et al., 2009b; Doron and Rosenblum, 2010; Sweetat et al., 2011). However, only the muscarinic-cholinergic and NMDARs have been extensively studied with regard to their roles in taste-memory acquisition, consolidation, and retention (Jones et al., 1999; Gutierrez et al., 2003; Nunez-Jaramillo et al., 2008; Rosenblum, 2008).

\section{GLUTAMATE}

Physical and chemical taste information is transferred from the oral cavity to the cortex via fast neurotransmission, mediated by the neurotransmitter glutamate, the main excitatory neurotransmitter in the mammalian CNS (Rosenblum, 2008; Rondard et al., 2011). Since the prominence of a given taste is hypothesized to be mediated via activation of the neuromodulatory system (e.g., Kaphzan et al., 2006), it is possible that the interaction between the two systems produces a long-term taste-memory trace; it is also likely that it coincides on specific neurons and probably molecules that can serve as coincidence detectors of the sensory input and its meaning (Kaphzan et al., 2006).

The glutamate receptor family comprises four types of receptors: alpha-amino-3-hydroxy-5-methyl-4-isoxazole propionic acid (AMPA), $N$-methyl-D-aspartic acid (NMDA), kainate, and mGluRs. AMPA, NMDA, and kainate receptors are ionotropic receptors, i.e., they can produce complex fast ion influx-mediated changes in the neuron, whereas mGluRs produce slow second messenger-mediated changes in the neuron by activating G-protein-coupled receptors (GPCRs; Rondard et al., 2011).

Glutamate and dopamine have been implicated in off-line processing and memory consolidation following CTA, by means of in vivo microdialysis and capillary electrophoresis (GuzmanRamos et al., 2010). In their study, Guzman-Ramos et al. (2010) demonstrated the occurrence of an amygdala-dependent dopamine and glutamate reactivation within the IC, about $45 \mathrm{~min}$ after the stimuli association. Furthermore, blockade of dopaminergic D1 and/or NMDARs before the off-line activity impaired long- but not STM, which suggests dependence on protein synthesis (Guzman-Ramos et al., 2010). In addition, dopamine and NMDA can synergistically activate extracellular signal-regulated kinase (ERK)/Mitogen-activated protein kinase (MAPK) signaling, which is necessary for the formation of long-term taste memory (Kaphzan et al., 2006, 2007).

Activation of NMDARs has been shown to be necessary for attenuation of the neophobic taste response in both the IC (Figueroa-Guzman et al., 2006) and the Bla (Figueroa-Guzman and Reilly, 2008). Acute microinfusions of MK-801, a noncompetitive NMDAR antagonist, into both brain regions revealed that although there was no effect on the initial magnitude of the neophobic response, attenuation of gustatory neophobia was prevented. Similarly, microinfusion of mGlu5-selective antagonist, 3-[2-methyl-1,3-thiazol-4yl)ethynyl]pyridine (MTEP), at 0, 1, or $5 \mu \mathrm{g}$ into the rat IC or Bla prior to CTA resulted in enhanced CTA performance in the case of the Bla, indicated by robust CTA followed by slower extinction than in control animals, in a dosedependent manner. Interestingly, MTEP microinfusion into the IC resulted in less robust aversion following CTA, in addition to enhanced extinction, in a dose-dependent manner (Simonyi et al., 2009). Previous studies that employed systemic administration of mGlu antagonists before CTA conditioning have demonstrated that activation of mGlu5, but not of mGlu1 receptors, was required for CTA learning (Schachtman et al., 2003). In addition, attenuation of CTA can be attained by microinjection of a broad-spectrum mGlu antagonist into the Bla (Yasoshima et al., 2000) or the IC (Berman et al., 2000).

mGlu5 receptors interact with NMDARs, and the two modulate one another's function in several brain regions in a mutually positive manner: stimulation of either receptor potentiates the other (Fowler et al., 2011). The two receptors are physically connected with each other through anchor proteins: mGlu5 receptor binds Homer proteins (Fagni et al., 2004), NMDAR interacts with postsynaptic density (PSD)-95, and Homer and PSD-95 can be clustered by Shank - all three of which are PSD proteins (Naisbitt et al., 1999; Tu et al., 1999). NMDA and mGlu5 can act synergistically to activate a number of proteins such as MAPKs, calcium/calmodulin-dependent protein kinase II (CaMKII), and CREB (Mao and Wang, 2002; Yang et al., 2004).

A plethora of studies using genetic, pharmacological, physiological, and biochemical approaches have indicated the critical roles played by mGlu5 and NMDA in both the IC and the hippocampus in acquisition and consolidation, but not retrieval, of memory of aversive tasks, specifically in avoidance learning and CTA (Schachtman et al., 2003; Cui et al., 2005; Gravius et al., 2005; Izquierdo et al., 2006; Simonyi et al., 2007, 2009; Barki-Harrington et al., 2009a; Nunez-Jaramillo et al., 2010). In a recent follow-up study employing co-administration of an mGlu5-receptor-positive allosteric modulator, 3-cyano- $N$-(1,3diphenyl-1H-pyrazol-5-yl) benzamide (CDPPB), and an NMDAR 


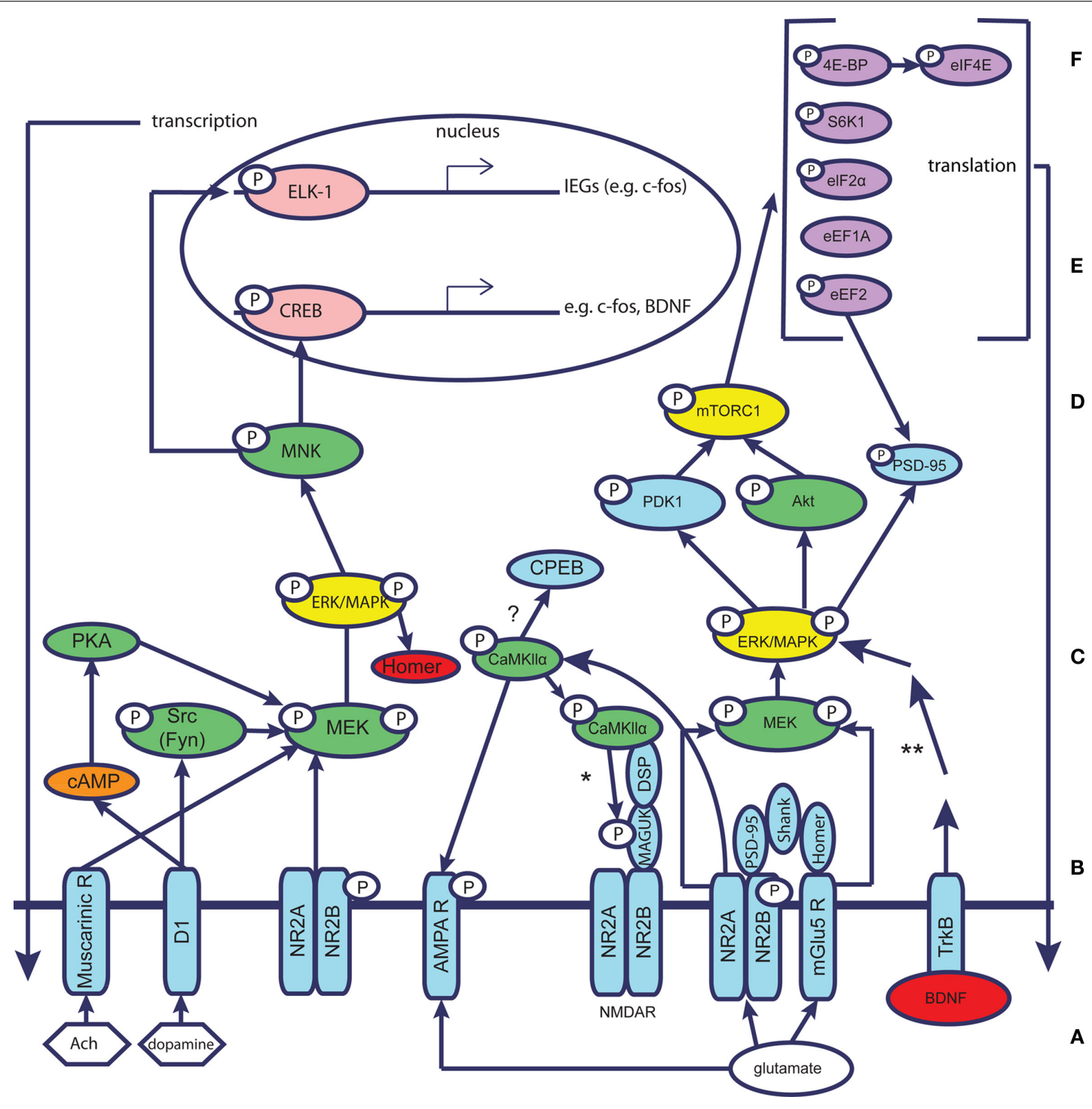

FIGURE 3 | Molecular mechanisms underlying taste learning in the gustatory cortex: schematic simplified representation assuming the different molecular events take place within the same neuron. Glutamate/neuromodulators (Ach, dopamine) reach the postsynaptic site and affect the neuron through specific receptors (NMDAR, AMPAR, mGluR, muscarinic receptors, dopamine receptors, e.g., D1). The receptors are linked to scaffold proteins that form the postsynaptic density (PSD), e.g., MAGUKs, Shank, Homer. MAGUKs are linked through distal scaffolding proteins (DSP) to CamKII. The complexes of receptors and PSD proteins activate signal transduction and hub molecules, which in turn activate transcription and translation regulation. This chain of events, according to our current understanding, results in a new cellular steady state. It is currently unknown whether all molecular processes depicted occur within a single neuron - a question that remains to be further explored. A, neuromodulators/glutamate; B, receptors; C, scaffold proteins; D, signal transduction and hub molecules; $\mathrm{E}$, translation regulation; $\mathrm{F}$, transcription. Key: neuromodulators - white hexagon; glutamate - white ellipse; receptors of neurotransmitters/neuromodulators - blue; representatives of major protein kinases and phosphatases that may have short-term (CamKIl $\alpha$ ) or long-term effects-green; protein translation machinery - purple; transcription factors - coral; immediate early genes - red; second messenger - orange. * CaMKII is known to phosphorylate PSD-95 and SAP-97, but it remains to be clarified whether it phosphorylates PSD-93 and SAP-102 as well. In addition, CamKII is well known to activate cytoplasmic polyadenylation element binding protein (CPEB) in other brain regions and in connection with other forms of learning, thereby affecting protein translation. **The BDNF pathway has been simplified; other proteins participate in this pathway. antagonist, MK-801, it was shown that NMDA and mGlu5 interacted functionally in CTA-conditioned rats. Whereas CDPPB administered by itself prior to the conditioning trial had no effect on CTA or hippocampus-dependent step-down inhibition, coadministration of the two compounds resulted in attenuation of learning deficits in both tasks (Fowler et al., 2011).
There is ample evidence in the literature for the importance of NMDAR, specifically its regulatory NR2B subunit, in taste learning. For example, CTA conditioning-induced long-lasting tyrosine phosphorylation of NR2B specifically in the IC (Rosenblum et al., 1995). Furthermore, local administration of (2R)-amino-5phosphonovaleric acid (APV), a reversibly selective competitive 
inhibitor of NMDAR, to the IC prior to CTA conditioning impaired CTA memory in a brain-region- and time-dependent manner (Rosenblum et al., 1995, 1996, 1997). In addition, whereas exposure to a novel taste, e.g., saccharin, increased phosphorylation in the NMDAR subunits, repeated doses of saccharin at the same concentration, which rendered the taste familiar, led to a dramatic decrease in the levels of serine phosphorylation of NR2A and NR2B subunits (Nunez-Jaramillo et al., 2008).

NR2B phosphorylation in the IC is not only correlated with but is necessary for taste learning, as has been demonstrated through pharmacological and genetic approaches: local administration of the tyrosine kinase inhibitor, genistein, to the IC prevented the increase in phosphorylation of NR2B on tyrosine 1472, and attenuated taste-memory formation (Barki-Harrington et al., 2009b). Additionally, whereas novel taste exposure has been recently demonstrated to induce intracellular redistribution of NR2A and NR2B subunits in the IC (Nunez-Jaramillo et al., 2008), microinjection of genistein to the IC altered this learning-induced distribution pattern of NMDAR, highlighting the importance of NR2B tyrosine phosphorylation after learning in determination of NMDAR distribution (Barki-Harrington et al., 2009b).

In another study, transgenic ( $\mathrm{Tg}$ ) mice over-expressing the NR2B subunit specifically in the forebrain (which includes the IC) were shown to have enhanced CTA, as well as slower extinction rates, although aversion levels were similar in Tg and wild-type (Wt) mice 30 days after the CTA conditioning. However, under the LI-CTA paradigm, the Tg mice did not differ from Wt mice in their aversion levels, and in a paradigm of two-taste LI-CTA (second order conditioning, in which the mice are exposed to both novel and familiar tastes) the $\mathrm{Tg}$ mice showed attenuation of enhanced CTA (Li et al., 2010).

\section{GABA AND ACh}

Although the involvement of glutamate receptors in the processing of taste learning in the GC has been extensively studied, other neurotransmitters have been implicated as well. Novel tastes have been shown to increase ACh levels in the rat IC, whereas a familiar taste did not (Miranda et al., 2000). Furthermore, pharmacological inactivation of the nucleus basalis magnocellularis, a cholinergic and GABAergic source in the basal forebrain, impaired CTA acquisition (Miranda and Bermudez-Rattoni, 1999). However, retrieval was not impaired by this manipulation. In addition, cholinergic activity mediated by muscarinic receptors in the IC has been shown to be necessary for acquisition and consolidation of contextual memory of inhibitory avoidance (Miranda and Bermudez-Rattoni, 2007).

Inhibitory GABAergic interneurons have been recently demonstrated to be activated in response to novel taste learning in a layer-specific manner hours after taste learning, which suggests that these neurons are involved not only in acquisition, but also in off-line processing and consolidation of taste information (Doron and Rosenblum, 2010). Electrophysiological studies in anesthetized rats revealed that excitatory propagation in the IC was primarily regulated by AMPA and $\mathrm{GABA}_{\mathrm{A}}$ receptors (Fujita et al., 2010). Another electrophysiological study in rat-cortex slices, which employed multiple-whole-cell patch-clamp recording from layer V GABAergic interneurons and pyramidal cells of rat IC, demonstrated that carbachol, a cholinergic agonist, increased the amplitude of unitary inhibitory postsynaptic currents (uIPSCs) in interneuron-to-interneuron synapses with higher paired-pulse ratios. However, the same compound induced dose-dependent suppression of uIPSCs in fast spiking of pyramidal cell synapses. This attenuation was mitigated by atropine, a muscarinic ACh receptor antagonist (Yamamoto et al., 2010), and the authors inferred that "carbachol facilitates GABA release in interneuron synapses with lower release probability, and cholinergic modulation of GABAergic synaptic transmission is differentially regulated depending on postsynaptic neuron subtypes." It is important to note that neurons projecting from one brain-region involved in taste learning to another (Figure 1) are inherently excitatory, however, neurons within a certain brain region may be inhibitory as well. The roles of inhibitory cortical neurons are yet to be determined.

\section{POSTSYNAPTIC DENSITY-95}

Postsynaptic density-95 (PSD-95), a membrane-associated guanylate kinase (MAGUK), is the major scaffolding protein in the excitatory PSD and a potent regulator of synaptic strength (Chen et al., 2011). It has been recently shown that $3 \mathrm{~h}$ following novel taste learning, expression levels of this protein were specifically elevated in the GC. This elevation has been shown to be necessary for acquisition of novel taste memory, but not for its retrieval, and it has not been observed in response to a familiar taste (Elkobi et al., 2008). Moreover, there was a correlative increase in PSD-95 association with tyrosine-phosphorylated NR2B following novel taste learning (Barki-Harrington et al., 2009b). A study concerning spatial learning, which is both hippocampus- and IC-dependent, has shown that water-maze training induced a translocation of NMDARs and PSD-95 to lipid raft membrane microdomains, concomitant with increased NR2B phosphorylation at tyrosine 1472 in the rat IC (Delint-Ramirez et al., 2008), similarly to novel taste learning, as mentioned above (Barki-Harrington et al., 2009b).

PSD-95 and other MAGUK family proteins, SAP-97 and PSD93, have been shown to interact with NMDAR, thereby regulating its function, e.g., all three inhibited NR2B-mediated endocytosis (Lavezzari et al., 2003). The MAGUK family proteins have been shown to mediate NMDAR clustering and/or trafficking by association with NMDAR NR2 subunits via their C-terminal glutamate serine (aspartate/glutamate) valine motifs. In addition, the MAGUK proteins interacted differentially with different NMDAR subtypes, comprised of differing receptor subunit combination (Cousins et al., 2008). Specifically, PSD-95 interacted with both NR2A and NR2B (Kornau et al., 1995), and this interaction could be modulated by either serine or tyrosine phosphorylation.

For example, CaMKII phosphorylated PSD-95 on serine residue, causing dissociation of NR2A, but not of NR2B from the NMDA-PSD-95 complex. In addition, PSD-95 itself functioned as a negative regulator of the tyrosine kinase Src, for which it served as a contact point to the NMDAR, thus enabling its regulation (Kalia et al., 2006). Moreover, phosphorylation of NR2A and NR2B and their associated proteins by Src or Fyn was found in some cases to enhance their association with PSD-95 (Rong et al., 2001; Zalewska et al., 2005). Other tyrosine kinases shown 
to interact with PSD-95 include c-Abl and Pyk2: the former regulated synaptic clustering of PSD-95 (de Arce et al., 2010); the latter underwent PSD-95-induced postsynaptic clustering and activation (Bartos et al., 2010). It has been suggested that the role of the PSD-95-NMDA complex is to protect NR2 subunits from undergoing cleavage by calcium-dependent proteases, and thereby to provide a mechanism for regulating NMDAR expression (Dong et al., 2004).

\section{THE ROLE OF THE MAPK/ERK PATHWAY IN THE GUSTATORY CORTEX}

Mitogen-activated protein kinases are a family of serine/threonine kinases implicated in regulation of cell proliferation and differentiation (Seger and Krebs, 1995; Belelovsky et al., 2007). Three major groups of MAPKs have been identified in mammalian cells: extracellular signal-regulated kinase (ERK), c-jun N-terminal kinase (JNK), and p38 MAP kinase. High levels of the ERK isoforms, ERK1 (p44 MAPK) and ERK2 (p42 MAPK), have been detected in neurons in the mature CNS (Fiore et al., 1993). ERK activity has been shown to be crucial for several forms of learning and memory, including fear conditioning, CTA memory, spatial memory, step-down inhibitory avoidance, and object recognition memory. In a study in which several pharmacological agents were locally injected into the rat IC, it was found that NMDARs, mGluRs, muscarinic, beta-adrenergic, and dopaminergic receptors were all implicated in acquisition of the new taste memory, but not in its retrieval, although these neurotransmitter/neuromodulator systems differed in their role in acquisition. In addition, it was demonstrated that of all the receptors studied, only NMDA and muscarinic receptors specifically mediated taste-dependent activation of ERK1-2, whereas dopaminergic receptors regulated the basal level of ERK1-2 activation (Berman et al., 2000). Several studies have demonstrated the differential role of ERK1 and 2 in cell growth and proliferation and synaptic plasticity. For example, ERK1 knockout mice displayed enhancement of striatumdependent long-term memory, in conjunction with facilitation of LTP in the nucleus accumbens, indicating the importance of ERK2 (Mazzucchelli et al., 2002; Vantaggiato et al., 2006).

ERK activation occurs downstream to neurotransmitter release and activation of the forebrain cholinergic neurons during and immediately after acquisition of an inhibitory avoidance response. ERK plays a major role in learning, by promoting cellular integration of divergent downstream effectors that may trigger differing responses, depending upon which subsets of scaffolding anchors, target proteins, and regulatory phosphatases are involved (Giovannini, 2006). MEK-ERK, the upstream kinase of ERK, is a crucial signal transduction cascade in synaptic plasticity and memory consolidation (Sweatt, 2001), and its inhibition affected both early and late phases of LTP in the hippocampus (Rosenblum et al., 2002).

Extracellular signal-regulated kinase activation was shown to be correlated with novel taste learning, although the amount of protein remained unchanged (Berman et al., 1998; Belelovsky et al., 2005). In addition, the expression of LTP in the GC was ERK-dependent, and operated in a positive feedback mode (Jones et al., 1999). In a recent study, it was shown that bilateral injection of U0126, a specific MEK inhibitor, to the GC prior to learning resulted in inhibition of ERK1/2, as well as attenuation of CTA (Rosenblum, 2008) and blockade of learning-induced elevation of PSD-95 $3 \mathrm{~h}$ following taste learning (Elkobi et al., 2008).

The various MAPKs are activated within differing time periods after novel taste learning; ERK activation appears to begin a few minutes up to $1 \mathrm{~h}$ following novel taste consumption (Rosenblum, 2008). It has been shown that novel taste consolidation requires the elevation of ERK1/2 activity in the IC 20 min after taste consumption. However, JNK1/2 was activated $1 \mathrm{~h}$ after novel taste learning, whereas p38 was not modified at any of the examined time points (Berman et al., 1998). Interestingly, the time scale of ERK activation was species-specific; it was shown to differ between mice and rats (Swank and Sweatt, 2001). ERK expression following taste learning is not only time-restricted, but also space-restricted; it was activated in the GC, but not in the hippocampus, after the same length of time following learning (Yefet et al., 2006). The various MAPKs also differed in BDNF-induced activation: intrahippocampal microinfusion of BDNF that aimed to induce LTP resulted in rapid phosphorylation of ERK and p38, but not of JNK (Ying et al., 2002). These effects were observed in the dentate gyrus, but not in other examined hippocampal regions, and were shown to be MEK-ERK-dependent.

Whereas the upstream regulation of ERK in the GC is well studied, our knowledge regarding its downstream targets remains fragmentary. MAPK substrate, ELK-1, a transcription factor regulating immediate early expression of genes via the serum response element (SRE) DNA consensus site (Besnard et al., 2011), has been shown to be phosphorylated in a time frame similar to that of ERK activation after novel taste learning, and neurotransmitters required for induction of LTM are also required for ELK-1 phosphorylation in the GC in response to taste learning (Berman et al., 2003). Further studies are needed to identify other possible targets of ERK and their mechanisms of action underlying taste processing in the GC.

\section{THE ROLE OF TRANSLATION REGULATION IN TASTE-MEMORY CONSOLIDATION}

The distinctive biochemical characteristic of memory consolidation is its dependence on synthesis of functional proteins in the relevant brain regions (Davis and Squire, 1984). Indeed, local application of anisomycin, a protein-synthesis inhibitor, to specific brain regions affected CTA in a dose-, site-, and time-dependent manner (Rosenblum et al., 1993; Meiri and Rosenblum, 1998). For instance, local application of anisomycin to the GC attenuated CTA and taste learning under the LI paradigm (Rosenblum et al., 1993); however, the same treatment had no effect on STM (Houpt and Berlin, 1999), which suggests that short-term taste memory is independent of protein synthesis. Temporally, taste learning is sensitive to protein-synthesis inhibitor(s) from just before learning until up to $100 \mathrm{~min}$ afterward (Rosenblum, 2008). In addition, extinction of CTA is dependent on functional protein synthesis in the prefrontal cortex (Akirav et al., 2006). It is generally accepted that protein translation affects LTM consolidation by modulation of synaptic strength, since protein-synthesis inhibitors prevented transformation of early LTP to late LTP. However, other modifications of intrinsic neuronal properties also subserve learning-related behavioral changes. For 
example, learning-induced reduction in the postburst after hyperpolarization (AHP) lasts for days after completion of training, and is implicated in maintenance of learned skills. It has been recently demonstrated that synaptic activation-induced shortterm postburst AHP reduction in hippocampal and pyramidal neurons could be transformed to a protein-synthesis-dependent long-term AHP reduction that persisted for long time periods (Cohen-Matsliah et al., 2010). Such learning-induced AHP reduction has been shown to be maintained by persistent activation of PKC and ERK in piriform cortex neurons (Seroussi et al., 2002; Cohen-Matsliah et al., 2007), but has been found to be CaMKII-independent (Liraz et al., 2009).

Translation consists of three phases: initiation, elongation, and termination. Of these, the initiation phase is the most tightly regulated, and is affected by phosphorylation of initiation factors (IFs) and ribosomal proteins (Proud, 2000). Initiation in eukaryotes serves as the rate-limiting step in protein synthesis, and therefore serves as an important target for translational control (Costa-Mattioli et al., 2009). There is considerable evidence in the literature that increased initiation results in enhanced learning, and vice versa. In knockout mice lacking the translation repressor eukaryotic initiation factor 4E-binding protein (4EBP2; Banko et al., 2007) or with reduced phosphorylation of eukaryotic initiation factor $2 \alpha$ (eIF2 $\alpha$; Costa-Mattioli et al., 2007), and therefore with enhanced initiation, no differences in taste recognition in parallel to enhanced CTA learning were observed; furthermore, other types of learning and plasticity in the consolidation phase were enhanced as well. Conversely, knockout mice lacking either S6K1 or S6K2, characterized by reduced initiation rates, exhibited impaired taste learning (Antion et al., 2008). In a model analogous to CTA in the chick, eukaryotic translation initiation factor 2B (eIF2B) was found to be both correlated with and necessary for taste-memory consolidation (Tirosh et al., 2007).

The second phase of translation, elongation, requires activity of elongation factors (EFs). Eukaryotic elongation factor 2 (eEF2) mediated ribosomal translocation (Ryazanov and Davydova, 1989) and was phosphorylated on Thr56 by a specific $\mathrm{Ca}^{2+} /$ calmodulin-dependent kinase. Phosphorylation of this kinase inhibited its activity and led to general inhibition of protein synthesis (Nairn and Palfrey, 1987). It has been shown that following novel taste learning, eEF2 phosphorylation was increased in the GC, indicating attenuation of translation elongation (Belelovsky et al., 2005). This finding, which is counter-intuitive, implies that the situation is more complex than implied by the simple model of "the more IFs, the better the taste learning" (Rosenblum, 2008). Nevertheless, there was increased initiation in the same samples, manifested as increased phosphorylation levels of ERK and S6K1 (Belelovsky et al., 2005).

Therefore, we have proposed a putative mechanism, by which increased initiation concomitant with decreased elongation in the same neurons in the GC might increase expression levels of mRNAs that are poorly initiated. This was reflected, for example, in the case of phosphorylation of the $\alpha$ subunit of eIF2 (eIF2 $\alpha$ ), which, in turn, led to suppression of general translation (Hinnebusch et al., 2000), concomitant with stimulation of translation of ATF4 (Lu et al., 2004; Vattem and Wek, 2004), which is required for late phase LTP and LTM (Bartsch et al., 1995; Chen et al., 2003).
The suggested mechanism could perform a switch-like function in expressing a specific set of $\mathrm{mRNAs}$ within a restricted time window in a cellular microdomain/s such as the synapse.

\section{MAMMALIAN TARGET OF RAPAMYCIN}

Some of the correlative changes that follow novel taste or CTA paradigms have been observed in proteins that are either direct or indirect targets of the mammalian target of rapamycin (mTOR), also known as FKBP-12-rapamycin-associated protein (FRAP), which consists of two TOR complexes (TORC) that differ in rapamycin sensitivity. TORC1 mediated rapamycin-sensitive TOR-shared signaling to the translation machinery, the transcription apparatus, and other targets (Loewith et al., 2002; Hay and Sonenberg, 2004), and its blockade by rapamycin interfered with translation of specific subpopulations of mRNA (Raught et al., 2001). Downstream targets of $\mathrm{mTOR}$ include ribosomal protein kinase (S6K1) and EF $1 \mathrm{~A}$ and 2 (eEF1A and eEF2), which are mostly involved in ribosome recruitment to mRNA, and regulation of both the initiation and elongation phases of translation (Hay and Sonenberg, 2004).

There is considerable evidence for the importance of the mTOR pathway in various forms of synaptic plasticity. In Aplysia, rapamycin application prevented long-term facilitation (Casadio et al., 1999), and in the rat hippocampal CA1 region, rapamycin blocked high-frequency stimulation (HFS) and BDNF-induced LTP (Tang et al., 2002). In addition, mTOR-dependent activation of dendritic S6K1 was shown to be necessary for the induction phase of protein-synthesis-dependent synaptic plasticity (Cammalleri et al., 2003).

It has been recently shown that following novel taste learning, two temporal waves of mTOR activation occurred in the GC (Belelovsky et al., 2009). Furthermore, it was shown that PSD-95 elevation in the GC $3 \mathrm{~h}$ following taste learning, which is necessary for LTM (Elkobi et al., 2008), was prevented following local application of rapamycin to the GC. Another study has shown, by means of HFS, an interesting interplay between ERK and mTOR pathways induced at CA3-CA1 synapses: whereas HFS induced LTP as well as translational proteins regulated by MTOR, the former induction was blocked by use of ERK inhibitors (Tsokas et al., 2007). Moreover, this study showed ERK to be not only correlated with, but necessary for mTOR stimulation by HFS via interaction with phosphoinositide-dependent kinase 1 (PDK1) and Akt, which are upstream to mTOR.

Other studies that used genetic and pharmacological approaches in the CA1 region of the hippocampus showed that activation of mTORC1 facilitated initiation of protein translation through phosphorylation and inhibition of eukaryotic initiation factor $4 \mathrm{E}$ (eIF4E)-binding proteins (4E-BP), which inhibit complex formation. Phosphorylation of eIF4E on Ser209 is ERKdependent and was closely linked with translation of specific mRNA subpopulations (Panja et al., 2009). Thus, it is currently accepted that ERK and $\mathrm{mTORC} 1$ synergistically regulate eIF4E and translation initiation in LTM and synaptic plasticity. It has been recently shown that Pin 1 inhibited protein-synthesis induced by glutamatergic signaling, and it was suggested that eIF4E and 4E$\mathrm{BP} 1 / 2$ mediated an increase in dendritic translation induced by Pin 1 inhibition (Westmark et al., 2010). 
It is important to note that other mechanisms have been implicated in translational control of long-lasting synaptic plasticity and memory, e.g., micro-RNA regulation (miRNA), and it is highly likely that they participate, at least in part, in taste learning as well. However, it remains to be clarified whether this is indeed the case.

\section{IMMEDIATE EARLY GENES AND CONVERGENCE OF CS/US}

Immediate early genes, activated transiently and rapidly by various cellular stimuli, are regulated at the transcription level. They provide a first response to these stimuli, in advance of protein synthesis. Many of the IEGs are transcription factors or other DNA-binding proteins (Plath et al., 2006). Expression levels of IEGs have been shown to increase in neuronal populations that subserve stimulus encoding in response to various kinds of behaviors (Campeau et al., 1991; Guzowski et al., 2005; Mattson et al., 2008; Koya et al., 2009). Several such IEGs have been implicated in taste memory, including cFOS, Activity-regulated cytoskeletonassociated protein (Arc/Arg3.1), Homer, and BDNF (Saddoris et al., 2009; Doron and Rosenblum, 2010), and have been shown to be elevated following other forms of learning as well. The aforementioned IEGs belong to a subclass termed effector neuronal IEGs, which mediate NMDAR-regulated phenotypic changes in the brain (Kaufmann and Worley, 1999). Many of these have been immunohistochemically detected in dendrites (Lyford et al., 1995; Tsui et al., 1996).

\section{ARC AND HOMER}

Arc and Homer are NMDAR-dependent markers for plasticity (Guzowski et al., 2001). Arc has been shown to play an important role in consolidation of synaptic plasticity and memories as an effector molecule downstream of many signaling pathways (Shepherd and Bear, 2011). It mediates synaptic homeostatic scaling of AMPA receptors, via a mechanism of interaction with the endocytosis machinery which, in turn, regulates AMPA receptor trafficking (Chowdhury et al., 2006; Plath et al., 2006; Shepherd et al., 2006). Additionally, Arc affects cytoskeletal dynamics, as local injection of Arc antisense into the dentate gyrus $2 \mathrm{~h}$ following LTP induction resulted in reversal of LTP, as well as dephosphorylation of actin depolymerization factor/cofilin, and loss of nascent filamentous actin (F-actin) at synaptic sites (Messaoudi et al., 2007; Bramham et al., 2010). In turn, these changes are instrumental in regulation of spine morphology by increasing spine density (Peebles et al., 2010). A recent electrophysiological study has shown that Arc synthesis was regulated by ERK-MNK signaling during LTP consolidation in the dentate gyrus in live rats. Although mTORC1 is activated following HFS stimulation, its pharmacological inhibition revealed that it is not essential for Arc synthesis and LTP (Panja et al., 2009).

Homer1 is a PSD scaffolding protein, involved in the regulation of synaptic metabotropic receptor function; it has been implicated in structural changes occurring at synapses during long-lasting neuronal plasticity and development (Xiao et al., 1998). Both Arc and Zif268 are required for generation of mRNA-dependent LTP. Additionally, intrahippocampal microinfusion of BDNF resulted in selective upregulation of Arc mRNA and protein, in addition to rapid and extensive delivery of Arc mRNA transcripts to granule cell dendrites (Ying et al., 2002).
A recent study has elegantly exploited the fact that Arc and Homerla show differential temporal expression patterns in activated neurons (Guzowski et al., 2001): it was used to mark neuronal ensembles in the GC and Bla that participated in processing novel taste information. Using in situ hybridization, Saddoris et al. (2009) showed that repeated exposure to a novel taste (sucrose) within the time frame required for temporal differentiation of Arc/Homerla resulted in increased IEG activity, as well as increased overlap of activated neuronal populations in the GC. In addition, they showed that odor cues associated with sucrose, but not with water, elicited potentiation of IEG activity in the GC similar to that of sucrose itself, independently of Bla. Such cell populations, responsive to both CS (taste) and US (odor), are held to be critical for further plasticity.

Another study employed compartmental analysis of temporal gene transcription fluorescence in situ hybridization (catFISH) for Arc, relying on complete translocation of Arc from the nucleus to the cytoplasm over $30 \mathrm{~min}$. This study, which applied Arc catFISH following a sucrose-conditioned odor preference test involving nine odor-taste pairings, showed, in contrast to the findings of Saddoris et al. (2009), that such a flavor experience paradigm induced a fourfold increase in the percentage of cells activated by both taste and odor stimulations in the Bla, but not in the IC (Desgranges et al., 2010). Furthermore, the authors showed that in odor-conditioned rats the number of cells responsive to one stimulus was unchanged. An earlier study, which used catFISH for Arc as well, also found that following CTA, specific Bla neuronal populations were responsive to both CS and US (Barot et al., 2008). Furthermore, this study demonstrated that when the LICTA paradigm was used, no coincident activation was detected. The identity of the cells expressing coincident activation remains to be further characterized.

\section{BRAIN-DERIVED NEUROTROPHIC FACTOR}

Brain-derived neurotrophic factor has emerged as a potent mediator both of synaptic plasticity on the cellular level, and of the interaction of an organism with its environment on the behavioral level (Moguel-Gonzalez et al., 2008). Along with its tyrosine kinase receptor TrkB, BDNF plays a critical role in activity-dependent plasticity processes, such as LTP, learning, and memory (Ma et al., 2011). Several studies have examined the effect of BDNF in the CTA paradigm. As mentioned above, BDNF-induced enhancement of CTA retention (Castillo et al., 2006), and this effect recently has been demonstrated to be dependent on activation of MAPK and phosphatidylinositol-3-kinase (PI-3K) in the IC (Castillo and Escobar, 2011). Furthermore, local administration of BDNF into the IC immediately after similar anisomycin administration performed prior to CTA training has been shown to reverse the anisomycin-induced CTA memory deficits almost to control levels. Taken together, these results imply that BDNF is a proteinsynthesis-dependent memory enhancer (Moguel-Gonzalez et al., 2008).

Although BDNF is an IEG, the time scale of its mRNA expression is somewhat longer than those of Arc or Homer. For instance, BDNF mRNA expression in the rat IC peaked $6 \mathrm{~h}$ after CTA, and began to return to base level after $8 \mathrm{~h}$ (Ma et al., 2011). Surprisingly, this study found that BDNF levels in the Bla remained 
unchanged, but an increase was observed in the central nuclei of the amygdala $(\mathrm{CeA})$, peaking at $4 \mathrm{~h}$. The authors showed that phosphorylated TrkB levels were elevated in the CeA long before the CTA-induced BDNF synthesis started, indicating a rapid activitydependent BDNF release, presumably independent of protein synthesis. These data suggest that BDNF secretion and synthesis may be spatially and temporally involved in CTA memory formation. These authors also demonstrated that BDNF secretion and synthesis were necessary for STM and LTM, respectively, and, in addition, that BDNF injected into the CeA enhanced the CTA memory. Furthermore, in another study it was shown that a human naturally occurring polymorphic variant of BDNF in knock-in mice (Val66Met) caused impairments in CTA extinction, but not in its acquisition or retention, whereas in humans, homozygosity to this variant is associated with altered hippocampal volume, hippocampal-dependent memory impairment, and susceptibility to neuropsychiatric disorders. On the cellular level, this polymorphism was associated with alterations in intracellular trafficking and activity-dependent secretion of Wt BDNF in neurosecretory cells and cortical neurons (Yu et al., 2009).

\section{FUTURE DIRECTIONS}

In all, a more thorough understanding of the molecular mechanisms underlying taste memory and of the functioning of the corresponding regulatory processes in relevant neurons that subserve taste-learning processing circuits should help to elucidate many important basic aspects of neuronal function. The main future questions and the directions of future research might be more general in their nature, reflecting the potential development of knowledge and understanding in the field of biological mechanisms of learning and memory, or they might address questions specific to the taste systems in the mammalian/human brain.

For example, dissection of the temporal dynamics of any memory - acquisition/consolidation and the establishment of remote memory retrieval, relearning, and reconsolidation - which was outlined in Figure 2 can be misleading. It is clear that acquisition

\section{REFERENCES}

Akirav, I., Khatsrinov, V., Vouimba, R. M., Merhav, M., Ferreira, G., Rosenblum, K., and Maroun, M. (2006). Extinction of conditioned taste aversion depends on functional protein synthesis but not on NMDA receptor activation in the ventromedial prefrontal cortex. Learn. Mem. 13, 254-258.

Alberini, C. M. (2011). The role of reconsolidation and the dynamic process of long-term memory formation and storage. Front. Behav. Neurosci. 5:2. doi:10.3389/fnbeh.2011.00012

Alme, M. N., Wibrand, K., Dagestad, G., and Bramham, C. R. (2007). Chronic fluoxetine treatment induces brain region-specific upregulation of genes associated with BDNF-induced long-term potentiation. Neural Plast. 2007, 26496.
Antion, M. D., Merhav, M., Hoeffer, C. A., Reis, G., Kozma, S. C., Thomas, G., Schuman, E. M., Rosenblum, K., and Klann, E. (2008). Removal of S6K1 and S6K2 leads to divergent alterations in learning, memory, and synaptic plasticity. Learn. Mem. 15, 29-38.

Banko, J. L., Merhav, M., Stern, E., Sonenberg, N., Rosenblum, K., and Klann, E. (2007). Behavioral alterations in mice lacking the translation repressor 4E-BP2. Neurobiol. Learn. Mem. 87, 248-256.

Barki-Harrington, L., Belelovsky, K., Doron, G., and Rosenblum, K. (2009a). "Molecular mechanisms of taste learning in the insular cortex and amygdala," in Conditioned Taste Aversion: Behavioral and Neural Processes, eds S. Reilly and T. R. Schachtman (Oxford: Oxford University Press), 341-363.

Barki-Harrington, L., Elkobi, A., Tzabary, T., and Rosenblum, K.

and retrieval are well defined in time. However, the consolidation phase is defined mainly in negative rather than positive terms; it is sensitive to various disruptions at different time points following acquisition, and the connections between the various molecular entities involved in the process of taste learning are not well described. In Figure 3 we outline some of the processes known to be taking place in the GC following novel taste learning. This offline processing of information in the brain may represent a more continuous rather than a phasic process. However, the mechanisms and molecular/cellular participants in these processes are yet to be identified (Figure 3). It is clear that in order to better understand the consolidation or off-line processes, it is necessary to enhance the measurements of the biochemical factors that are correlated with and necessary for taste learning, and to improve their resolution to a few cubic micrometers or to cellular/subcellular levels. The tools for this kind of in vivo single-cell analysis have been dramatically improved recently, and will be used to obtain better descriptions of the molecular and cellular mechanisms underlying learning and memorizing processes. Moreover, we and others will aim to identify the specific circuit or neuronal ensemble involved in creation and maintenance of any given memory and its value.

Other aims, more specific to the taste system, will be to understand the neuronal mechanisms underlying the taste-memory condition of waiting "on hold" for many hours, with its physical and chemical information as a conditioned stimulus, pending arrival of the unconditioned stimulus or the digestive information that will enable the taste to be tagged as safe or dangerous. This specific and unique ability of taste-learning beautifully represents the flexibility of the neuronal system underlying learning and memory processes, and can also teach us about the limits of the neuronal systems abilities to create simple and associative memories.

\section{ACKNOWLEDGMENTS}

This work was supported by DIP (RO 3971/1-1), ISF (1305/08), and European Union Seventh Framework Program EUROSPIN (Contract HEALTH-F2-2009-241498) grants for Kobi Rosenblum.

(2009b). Tyrosine phosphorylation of the $2 \mathrm{~B}$ subunit of the NMDA receptor is necessary for taste memory formation. J. Neurosci. 29, 9219-9226.

Barot, S. K., Kyono, Y., Clark, E. W., and Bernstein, I. L. (2008). Visualizing stimulus convergence in amygdala neurons during associative learning. Proc. Natl. Acad. Sci. U.S.A. 105, 20959-20963.

Bartos, J. A., Ulrich, J. D., Li, H., Beazely, M. A., Chen, Y., Macdonald, J. F., and Hell, J. W. (2010). Postsynaptic clustering and activation of Pyk2 by PSD-95. J. Neurosci. 30, 449-463.

Bartsch, D., Ghirardi, M., Skehel, P. A., Karl, K. A., Herder, S. P., Chen, M., Bailey, C. H., and Kandel, E. R. (1995). Aplysia CREB2 represses long-term facilitation: relief of repression converts transient facilitation into long-term functional and structural change. Cell 83, 979-992.
Belelovsky, K., Elkobi, A., Kaphzan, H. Nairn, A. C., and Rosenblum, K. (2005). A molecular switch for translational control in taste memory consolidation. Eur. J. Neurosci. 22, 2560-2568.

Belelovsky, K., Kaphzan, H., Elkobi, A., and Rosenblum, K. (2009). Biphasic activation of the mTOR pathway in the gustatory cortex is correlated with and necessary for taste learning. J. Neurosci. 29, 7424-7431.

Belelovsky, K., Maroun, M., and Rosenblum, K. (2007). MAPK activation in the hippocampus in vivo is correlated with experimental setting. Neurobiol. Learn. Mem. 88, 58-64.

Berman, D. E., Hazvi, S., Neduva, V., and Dudai, Y. (2000). The role of identified neurotransmitter systems in the response of insular cortex to unfamiliar taste: activation of ERK1-2 and formation of a memory trace. J. Neurosci. 20, 7017-7023. 
Berman, D. E., Hazvi, S., Rosenblum, K., Seger, R., and Dudai, Y. (1998). Specific and differential activation of mitogen-activated protein kinase cascades by unfamiliar taste in the insular cortex of the behaving rat. J. Neurosci. 18, 10037-10044.

Berman, D. E., Hazvi, S., Stehberg, J., Bahar, A., and Dudai, Y. (2003). Conflicting processes in the extinction of conditioned taste aversion: behavioral and molecular aspects of latency, apparent stagnation, and spontaneous recovery. Learn. Mem. 10, 16-25.

Besnard, A., Galan-Rodriguez, B., Vanhoutte, P., and Caboche, J. (2011). Elk-1 a transcription factor with multiple facets in the brain. Front. Neurosci. 5:35. doi:10.3389/fnins.2011.00035

Bliss, T. V., and Collingridge, G. L. (1993). A synaptic model of memory: long-term potentiation in the hippocampus. Nature 361, 31-39.

Bramham, C. R. (2007). Control of synaptic consolidation in the dentate gyrus: mechanisms, functions, and therapeutic implications. Prog. Brain Res. 163, 453-471.

Bramham, C. R., Alme, M. N., Bittins, M., Kuipers, S. D., Nair, R. R., Pai, B., Panja, D., Schubert, M., Soule, J., Tiron, A., and Wibrand, K. (2010). The Arc of synaptic memory. Exp. Brain Res. 200, 125-140.

Bures, J., Bermudez-Rattoni, F., and Yamamoto, Y. (1998). Conditioned Taste Aversion: Memory of a Special Kind. Oxford, NY: Oxford University Press.

Burwell, R. D. (2001). Borders and cytoarchitecture of the perirhinal and postrhinal cortices in the rat. $J$. Comp. Neurol. 437, 17-41.

Cammalleri, M., Lutjens, R., Berton, F., King, A. R., Simpson, C., Francesconi, W., and Sanna, P. P. (2003). Time-restricted role for dendritic activation of the mTORp70S6K pathway in the induction of late-phase long-term potentiation in the CA1. Proc. Natl. Acad. Sci. U.S.A. 100, 14368-14373.

Campeau, S., Hayward, M. D., Hope, B. T., Rosen, J. B., Nestler, E. J., and Davis, M. (1991). Induction of the cfos proto-oncogene in rat amygdala during unconditioned and conditioned fear. Brain Res. 565, 349-352.

Carleton, A., Accolla, R., and Simon, S. A. (2010). Coding in the mammalian gustatory system. Trends Neurosci. 33, 326-334.

Casadio, A., Martin, K. C., Giustetto, M., Zhu, H., Chen, M., Bartsch, D., Bailey, C. H., and Kandel, E. R. (1999).
A transient, neuron-wide form of CREB-mediated long-term facilitation can be stabilized at specific synapses by local protein synthesis. Cell 99, 221-237.

Castillo, D. V., and Escobar, M. L. (2011). A role for MAPK and PI-3K signaling pathways in brain-derived neurotrophic factor modification of conditioned taste aversion retention. Behav. Brain Res. 217, 248-252.

Castillo, D. V., Figueroa-Guzman, Y., and Escobar, M. L. (2006). Brain-derived neurotrophic factor enhances conditioned taste aversion retention. Brain Res. 1067, 250-255.

Chen, A., Muzzio, I. A., Malleret, G., Bartsch, D., Verbitsky, M., Pavlidis, P., Yonan, A. L., Vronskaya, S., Grody, M. B., Cepeda, I., Gilliam, T. C., and Kandel, E. R. (2003). Inducible enhancement of memory storage and synaptic plasticity in transgenic mice expressing an inhibitor of ATF4 (CREB-2) and C/EBP proteins. Neuron 39, 655-669.

Chen, A. P., Ohno, M., Giese, K. P., Kuhn, R., Chen, R. L., and Silva, A. J. (2006). Forebrain-specific knockout of B-raf kinase leads to deficits in hippocampallong-term potentiation, learning, and memory. J. Neurosci. Res. 83, 28-38.

Chen, X., Nelson, C. D., Li, X., Winters, C. A., Azzam, R., Sousa, A. A., Leapman, R. D., Gainer, H., Sheng, M., and Reese, T. S. (2011). PSD-95 is required to sustain the molecular organization of the postsynaptic density. J. Neurosci. 31, 6329-6338.

Chowdhury, S., Shepherd, J. D., Okuno, H., Lyford, G., Petralia, R. S., Plath, N., Kuhl, D., Huganir, R. L., and Worley, P. F. (2006). Arc/Arg3.1 interacts with the endocytic machinery to regulate AMPA receptor trafficking. Neuron 52, 445-459.

Cohen-Matsliah, S. I., Brosh, I., Rosenblum, K., and Barkai, E. (2007). A novel role for extracellular signal-regulated kinase in maintaining long-term memory-relevant excitability changes. J. Neurosci. 27, 12584-12589.

Cohen-Matsliah, S. I., Motanis, H., Rosenblum, K., and Barkai, E. (2010). A novel role for protein synthesis in long-term neuronal plasticity: maintaining reduced postburst afterhyperpolarization. J. Neurosci. 30, 4338-4342.

Collingridge, G. L., Isaac, J. T., and Wang, Y. T. (2004). Receptor trafficking and synaptic plasticity. Nat. Rev. Neurosci. 5, 952-962.

Costa-Mattioli, M., Gobert, D., Stern, E., Gamache, K., Colina, R., Cuello, C., Sossin, W., Kaufman, R., Pelletier, J.,
Rosenblum, K., Krnjevic, K., Lacaille, J. C., Nader, K., and Sonenberg, N. (2007). eIF2alpha phosphorylation bidirectionally regulates the switch from short- to long-term synaptic plasticity and memory. Cell 129 , 195-206.

Costa-Mattioli, M., Sossin, W. S., Klann, E., and Sonenberg, N. (2009). Translational control of long-lasting synaptic plasticity and memory. Neuron 61, 10-26.

Cousins, S. L., Papadakis, M., Rutter, A. R., and Stephenson, F A. (2008). Differential interaction of NMDA receptor subtypes with the post-synaptic density-95 family of membrane associated guanylate kinase proteins. J. Neurochem. 104 903-913.

Cui, Z., Lindl, K. A., Mei, B., Zhang, S. and Tsien, J. Z. (2005). Requirement of NMDA receptor reactivation for consolidation and storage of nondeclarative taste memory revealed by inducible NR1 knockout. Eur. J. Neurosci. 22, 755-763.

Davis, H. P., and Squire, L. R. (1984). Protein synthesis and memory: a review. Psychol. Bull. 96, 518-559.

de Arce, K. P., Varela-Nallar, L., Farias, O., Cifuentes, A., Bull, P., Couch, B. A., Koleske, A. J., Inestrosa, N. C., and Alvarez, A. R. (2010). Synaptic clustering of PSD-95 is regulated by c-Abl through tyrosine phosphorylation. J. Neurosci. 30, 3728-3738.

De la Cruz, V., Rodriguez-Ortiz, C. J., Balderas, I., and Bermudez-Rattoni, F. (2008). Medial temporal lobe structures participate differentially in consolidation of safe and aversive taste memories. Eur. J. Neurosci. 28 1377-1381.

Delint-Ramirez, I., Salcedo-Tello, P., and Bermudez-Rattoni, F. (2008). Spatial memory formation induces recruitment of NMDA receptor and PSD95 to synaptic lipid rafts. J. Neurochem. 106, 1658-1668.

Desgranges, B., Ramirez-Amaya, V. Ricano-Cornejo, I., Levy, F., and Ferreira, G. (2010). Flavor preference learning increases olfactory and gustatory convergence onto single neurons in the basolateral amygdala but not in the insular cortex in rats. PLoS ONE 5, e10097. doi:10.1371/journal.pone.0010097

Dong, Y. N., Waxman, E. A., and Lynch, D. R. (2004). Interactions of postsynaptic density-95 and the NMDA receptor 2 subunit control calpain-mediated cleavage of the NMDA receptor. J. Neurosci. 24, 11035-11045.

Doron, G., and Rosenblum, K. (2010). c-Fos expression is elevated in
GABAergic interneurons of the gustatory cortex following novel taste learning. Neurobiol. Learn. Mem. 94, 21-29.

Dudai, Y. (2004). The neurobiology of consolidations, or, how stable is the engram? Annu. Rev. Psychol. 55, 51-86.

Elkobi, A., Ehrlich, I., Belelovsky, K., Barki-Harrington, L., and Rosenblum, K. (2008). ERK-dependent PSD-95 induction in the gustatory cortex is necessary for taste learning, but not retrieval. Nat. Neurosci. 11, 1149-1151.

Escobar, M. L., Alcocer, I., and Bermudez-Rattoni, F. (2002). In vivo effects of intracortical administration of NMDA and metabotropic glutamate receptors antagonists on neocortical long-term potentiation and conditioned taste aversion. Behav. Brain Res. 129, 101-106.

Escobar, M. L., Alcocer, I., and Chao, V. (1998). The NMDA receptor antagonist CPP impairs conditioned taste aversion and insular cortex longterm potentiation in vivo. Brain Res. 812, 246-251.

Escobar, M. L., and Bermudez-Rattoni, F. (2000). Long-term potentiation in the insular cortex enhances conditioned taste aversion retention. Brain Res. 852, 208-212.

Escobar, M. L., Figueroa-Guzman, Y., and Gomez-Palacio-Schjetnan, A (2003). In vivo insular cortex LTP induced by brain-derived neurotrophic factor. Brain Res. 991, 274-279.

Fagni, L., Ango, F., Perroy, J., and Bockaert, J. (2004). Identification and functional roles of metabotropic glutamate receptor-interacting proteins. Semin. Cell Dev. Biol. 15, 289-298.

Feldman, D. E. (2009). Synaptic mechanisms for plasticity in neocortex. Annu. Rev. Neurosci. 32, 33-55.

Figueroa-Guzman, Y., Kuo, J. S., and Reilly, S. (2006). NMDA receptor antagonist MK-801 infused into the insular cortex prevents the attenuation of gustatory neophobia in rats. Brain Res. 1114, 183-186.

Figueroa-Guzman, Y., and Reilly, S. (2008). NMDA receptors in the basolateral amygdala and gustatory neophobia. Brain Res. 1210 200-203.

Fiore, R. S., Bayer, V. E., Pelech, S. L., Posada, J., Cooper, J. A., and Baraban, J. M. (1993). P42 mitogenactivated protein kinase in brain: prominent localization in neuronal cell bodies and dendrites. Neuroscience 55, 463-472. 
Fowler, S. W., Ramsey, A. K., Walker, J. M., Serfozo, P., Olive, M. F., Schachtman, T. R., and Simonyi, A. (2011). Functional interaction of mGlu5 and NMDA receptors in aversive learning in rats. Neurobiol. Learn. Mem. 95, 73-79.

Frank, M. E., Lundy, R. F. Jr., and Contreras, R. J. (2008). Cracking taste codes by tapping into sensory neuron impulse traffic. Prog. Neurobiol. 86, 245-263.

Fujita, S., Adachi, K., Koshikawa, N., and Kobayashi, M. (2010). Spatiotemporal dynamics of excitation in rat insular cortex: intrinsic corticocortical circuit regulates caudalrostro excitatory propagation from the insular to frontal cortex. Neuroscience 165, 278-292.

Garcia, J., Kimeldorf, D. J., and Koelling, R. A. (1955). Conditioned aversion to saccharin resulting from exposure to gamma radiation. Science 122, 157-158.

Gibb, S. J., Wolff, M., and DalrympleAlford, J. C. (2006). Odour-place paired-associate learning and limbic thalamus: comparison of anterior, lateral and medial thalamic lesions. Behav. Brain Res. 172, 155-168.

Giovannini, M. G. (2006). The role of the extracellular signal-regulated kinase pathway in memory encoding. Rev. Neurosci. 17, 619-634.

Gravius, A., Pietraszek, M., Schafer, D., Schmidt, W. J., and Danysz, W. (2005). Effects of mGlu1 and mGlu5 receptor antagonists on negatively reinforced learning. Behav. Pharmacol. 16, 113-121.

Gutierrez, R., Tellez, L. A., and Bermudez-Rattoni, F. (2003). Blockade of cortical muscarinic but not NMDA receptors prevents a novel taste from becoming familiar. Eur. J. Neurosci. 17, 1556-1562.

Guzman-Ramos, K., Osorio-Gomez, D., Moreno-Castilla, P., and BermudezRattoni, F. (2010). Off-line concomitant release of dopamine and glutamate involvement in taste memory consolidation. J. Neurochem. 114, 226-236.

Guzowski, J. F., McNaughton, B. L., Barnes, C. A., and Worley, P. F. (2001). Imaging neural activity with temporal and cellular resolution using FISH. Curr. Opin. Neurobiol. 11, 579-584.

Guzowski, J. F., Timlin, J. A., Roysam, B., McNaughton, B. L., Worley, P. F., and Barnes, C. A. (2005). Mapping behaviorally relevant neural circuits with immediate-early gene expression. Curr. Opin. Neurobiol. 15, 599-606.
Hay, N., and Sonenberg, N. (2004). Upstream and downstream of mTOR. Genes Dev. 18, 1926-1945.

Hinnebusch, J., Cherepanov, P., Du, Y., Rudolph, A., Dixon, J. D., Schwan, T., and Forsberg, A. (2000). Murine toxin of Yersinia pestis shows phospholipase $\mathrm{D}$ activity but is not required for virulence in mice. Int. J. Med. Microbiol. 290, 483-487.

Houpt, T. A., and Berlin, R. (1999). Rapid, labile, and protein synthesisindependent short-term memory in conditioned taste aversion. Learn. Mem. 6, 37-46.

Izquierdo, I., Bevilaqua, L. R., Rossato, J. I., Bonini, J. S., Da Silva, W. C., Medina, J. H., and Cammarota, M. (2006). The connection between the hippocampal and the striatal memory systems of the brain: a review of recent findings. Neurotox. Res. 10, 113-121.

Jones, M. W., French, P. J., Bliss, T. V., and Rosenblum, K. (1999). Molecular mechanisms of long-term potentiation in the insular cortex in vivo. J. Neurosci. 19, RC36.

Kalia, L. V., Pitcher, G. M., Pelkey, K. A., and Salter, M. W. (2006). PSD-95 is a negative regulator of the tyrosine kinase Src in the NMDA receptor complex. EMBO J. 25, 4971-4982.

Kandel, E. R. (2001). The molecular biology of memory storage: a dialogue between genes and synapses. Science 294, 1030-1038.

Kaphzan, H., Doron, G., and Rosenblum, K. (2007). Co-application of NMDA and dopamine-induced rapid translation of RSK2 in the mature hippocampus. J. Neurochem. 103, 388-399.

Kaphzan, H., ORiordan, K. J., Mangan, K. P., Levenson, J. M., and Rosenblum, K. (2006). NMDA and dopamine converge on the NMDAreceptor to induce ERK activation and synaptic depression in mature hippocampus. PLoS ONE 1, e138. doi:10.1371/journal.pone.0000138

Kaufmann, W. E., and Worley, P. F. (1999). Neural activity and immediate early gene expression in the cerebral cortex. Dev. Disabil. Res. Rev. 5, 41-50.

Koh, M. T., and Bernstein, I. L. (2005). Mapping conditioned taste aversion associations using c-Fos reveals a dynamic role for insular cortex. Behav. Neurosci. 119, 388-398.

Kornau, H. C., Schenker, L. T., Kennedy, M. B., and Seeburg, P. H. (1995). Domain interaction between NMDA receptor subunits and the postsynaptic density protein PSD-95. Science 269, 1737-1740.
Koya, E., Golden, S. A., Harvey, B. K., Guez-Barber, D. H., Berkow, A., Simmons, D. E., Bossert, J. M., Nair, S. G., Uejima, J. L., Marin, M. T. Mitchell, T. B., Farquhar, D., Ghosh, S. C., Mattson, B. J., and Hope, B. T. (2009). Targeted disruption of cocaine-activated nucleus accumbens neurons prevents contextspecific sensitization. Nat. Neurosci. 12, 1069-1073.

Lamprecht, R., and Dudai, Y. (1996). Transient expression of c-Fos in rat amygdala during training is required for encoding conditioned taste aversion memory. Learn. Mem. 3, 31-41.

Lavezzari, G., McCallum, J., Lee, R. and Roche, K. W. (2003). Differential binding of the AP-2 adaptor complex and PSD-95 to the C-terminus of the NMDA receptor subunit NR2B regulates surface expression. Neuropharmacology 45 729-737.

Li, S., Gu, Y., Meng, B., Mei, B., and Li, F. (2010). The different effects of overexpressing murine NMDA receptor 2B subunit in the forebrain on conditioned taste aversion. Brain Res. 1351, 165-171.

Lin, P. Y., Wang, S. P., Tai, M. Y., and Tsai, Y. F. (2010). Differential involvement of medial prefrontal cortex and basolateral amygdala extracellular signal-regulated kinase in extinction of conditioned taste aversion is dependent on different intervals of extinction following conditioning. Neuroscience 171, 125-133.

Lindquist, D. H., Vogel, R. W., and Steinmetz, J. E. (2009). Associative and non-associative blinking in classically conditioned adult rats. Physiol. Behav. 96, 399-411.

Liraz, O., Rosenblum, K., and Barkai, E. (2009). CAMKII activation is not required for maintenance of learninginduced enhancement of neuronal excitability. PLoS ONE 4, e4289. doi:10.1371/journal.pone.0004289

Loewith, R., Jacinto, E., Wullschleger, S., Lorberg, A., Crespo, J. L., Bonenfant, D., Oppliger, W., Jenoe, P., and Hall, M. N. (2002). Two TOR complexes, only one of which is rapamycin sensitive, have distinct roles in cell growth control. Mol. Cell 10, 457-468.

Lu, P. D., Harding, H. P., and Ron, D. (2004). Translation reinitiation at alternative open reading frames regulates gene expression in an integrated stress response. J. Cell Biol. 167, 27-33.

Lubow, R. E. (1989). Latent Inhibition and Conditioned Attention Theory.
Cambridge: Cambridge University Press.

Lyford, G. L., Yamagata, K., Kaufmann, W. E., Barnes, C. A., Sanders, L. K. Copeland, N. G., Gilbert, D. J., Jenkins, N. A., Lanahan, A. A., and Worley, P. F. (1995). Arc, a growth factor and activity-regulated gene, encodes a novel cytoskeleton-associated protein that is enriched in neuronal dendrites. Neuron 14, 433-445.

Ma, L., Wang, D. D., Zhang, T. Y., Yu, H., Wang, Y., Huang, S. H., Lee, F. S., and Chen, Z. Y. (2011). Region-specific involvement of BDNF secretion and synthesis in conditioned taste aversion memory formation. J. Neurosci. 31, 2079-2090.

Malenka, R. C., and Bear, M. F. (2004). LTP and LTD: an embarrassment of riches. Neuron 44, 5-21.

Mao, L., and Wang, J. Q. (2002). Interactions between ionotropic and metabotropic glutamate receptors regulate cAMP response elementbinding protein phosphorylation in cultured striatal neurons. Neuroscience 115, 395-402.

Mattson, B. J., Koya, E., Simmons, D. E., Mitchell, T. B., Berkow, A., Crombag, H. S., and Hope, B. T. (2008). Context-specific sensitization of cocaine-induced locomotor activity and associated neuronal ensembles in rat nucleus accumbens. Eur. J. Neurosci. 27, 202-212.

Mazzucchelli, C., Vantaggiato, C., Ciamei, A., Fasano, S., Pakhotin, P., Krezel, W., Welzl, H., Wolfer, D. P., Pages, G., Valverde, O., Marowsky, A., Porrazzo, A., Orban, P. C., Maldonado, R., Ehrengruber, M. U., Cestari, V., Lipp, H. P., Chapman, P. F., Pouyssegur, J., and Brambilla, R. (2002). Knockout of ERK1 MAP kinase enhances synaptic plasticity in the striatum and facilitates striatal-mediated learning and memory. Neuron 34 807-820.

McGaugh, J. L. (2000). Memory - a century of consolidation. Science 287 , 248-251.

McGeachie, A. B., Cingolani, L. A., and Goda, Y. (2011). A stabilising influence: integrins in regulation of synaptic plasticity. Neurosci. Res. 70, 24-29.

Mei, F., Nagappan, G., Ke, Y., Sacktor, T. C., and Lu, B. (2011). BDNF facilitates L-LTP maintenance in the absence of protein synthesis through PKMzeta. PLoS ONE 6, e21568. doi:10.1371/journal.pone.0021568

Meiri, N., and Rosenblum, K. (1998). Lateral ventricle injection of the protein synthesis inhibitor anisomycin impairs long-term memory in a 
spatial memory task. Brain Res. 789, 48-55.

Merhav, M., Kuulmann-Vander, S., Elkobi, A., Jacobson-Pick, S., Karni, A., and Rosenblum, K. (2006). Behavioral interference and $\mathrm{C} / \mathrm{EBPb}$ ta expression in the insular-cortex reveal a prolonged time period for taste memory consolidation. Learn. Mem. 13, 571-574.

Merhav, M., and Rosenblum, K. (2008). Facilitation of taste memory acquisition by experiencing previous novel taste is protein-synthesis dependent. Learn. Mem. 15, 501-507.

Messaoudi, E., Kanhema, T., Soule, J., Tiron, A., Dagyte, G., da Silva, B., and Bramham, C. R. (2007). Sustained Arc/Arg3.1 synthesis controls long-term potentiation consolidation through regulation of local actin polymerization in the dentate gyrus in vivo. J. Neurosci. 27, 10445-10455.

Miranda, M. I., and Bermudez-Rattoni, F. (1999). Reversible inactivation of the nucleus basalis magnocellularis induces disruption of cortical acetylcholine release and acquisition, but not retrieval, of aversive memories. Proc. Natl. Acad. Sci. U.S.A. 96, 6478-6482.

Miranda, M. I., and Bermudez-Rattoni, F. (2007). Cholinergic activity in the insular cortex is necessary for acquisition and consolidation of contextual memory. Neurobiol. Learn. Mem. 87, 343-351.

Miranda, M. I., Ramirez-Lugo, L., and Bermudez-Rattoni, F. (2000). Cortical cholinergic activity is related to the novelty of the stimulus. Brain Res. 882, 230-235.

Miranda, M. I., Rodriguez-Garcia, G., Reyes-Lopez, J. V., Ferry, B., and Ferreira, G. (2008). Differential effects of beta-adrenergic receptor blockade in basolateral amygdala or insular cortex on incidental and associative taste learning. Neurobiol. Learn. Mem. 90, 54-61.

Moguel-Gonzalez, M., Gomez-PalacioSchjetnan, A., and Escobar, M. L. (2008). BDNF reverses the CTA memory deficits produced by inhibition of protein synthesis. Neurobiol. Learn. Mem. 90, 584-587.

Morris, R., Frey, S., Kasambira, T., and Petrides, M. (1999). Ibotenic acid lesions of the basolateral, but not the central, amygdala interfere with conditioned taste aversion: evidence from a combined behavioral and anatomical tract-tracing investigation. Behav. Neurosci. 113, 291-302.

Morris, R. G. (2006). Elements of a neurobiological theory of hippocampal function: the role of synaptic plasticity, synaptic tagging and schemas. Eur. J. Neurosci. 23, 2829-2846.

Nachman, M., and Ashe, J. H. (1974). Effects of basolateral amygdala lesions on neophobia, learned taste aversions, and sodium appetite in rats. J. Comp. Physiol. Psychol. 87, 622-643.

Nairn, A. C., and Palfrey, H. C. (1987). Identification of the major $\mathrm{Mr}$ 100,000 substrate for calmodulindependent protein kinase III in mammalian cells as elongation factor-2. J. Biol. Chem. 262, 17299-17303.

Naisbitt, S., Kim, E., Tu, J. C., Xiao, B., Sala, C., Valtschanoff, J., Weinberg, R. J., Worley, P. F., and Sheng, M. (1999). Shank, a novel family of postsynaptic density proteins that binds to the NMDA receptor/PSD95/GKAP complex and cortactin. Neuron 23, 569-582.

Navakkode, S., Sajikumar, S., Sacktor, T. C., and Frey, J. U. (2010). Protein kinase Mzeta is essential for the induction and maintenance of dopamine-induced longterm potentiation in apical CA1 dendrites. Learn. Mem. 17, 605-611.

Neves, G., Cooke, S. F., and Bliss, T. V. (2008). Synaptic plasticity, memory and the hippocampus: a neural network approach to causality. Nat. Rev. Neurosci. 9, 65-75.

Nunez-Jaramillo, L., Jimenez, B., Ramirez-Munguia, N., DelintRamirez, I., Luna-Illades, C., Tapia, R., and Bermudez-Rattoni, F. (2008). Taste novelty induces intracellular redistribution of NR2A and NR2B subunits of NMDA receptor in the insular cortex. Brain Res. 1215, 116-122.

Nunez-Jaramillo, L., Ramirez-Lugo, L., Herrera-Morales, W., and Miranda, M. I. (2010). Taste memory formation: latest advances and challenges. Behav. Brain Res. 207, 232-248.

Panja, D., Dagyte, G., Bidinosti, M., Wibrand, K., Kristiansen, A. M., Sonenberg, N., and Bramham, C. R. (2009). Novel translational control in Arc-dependent long term potentiation consolidation in vivo. J. Biol. Chem. 284, 31498-31511.

Parvez, S., Ramachandran, B., and Frey, J. U. (2010). Functional differences between and across different regions of the apical branch of hippocampal CAl dendrites with respect to long-term depression induction and synaptic cross-tagging. J. Neurosci. 30, 5118-5123.

Pastalkova, E., Serrano, P., Pinkhasova, D., Wallace, E., Fenton, A. A., and Sacktor, T. C. (2006). Storage of spatial information by the maintenance mechanism of LTP. Science 313, 1141-1144.

Peebles, C. L., Yoo, J., Thwin, M. T., Palop, J. J., Noebels, J. L., and Finkbeiner, S. (2010). Arc regulates spine morphology and maintains network stability in vivo. Proc. Natl. Acad. Sci. U.S.A. 107, 18173-18178.

Plath, N., Ohana, O., Dammermann, B., Errington, M. L., Schmitz, D., Gross, C., Mao, X., Engelsberg, A., Mahlke, C., Welzl, H., Kobalz, U., Stawrakakis, A., Fernandez, E., Waltereit, R., Bick-Sander, A., Therstappen, E., Cooke, S. F., Blanquet, V., Wurst, W., Salmen, B., Bosl, M. R., Lipp, H. P., Grant, S. G., Bliss, T. V., Wolfer, D. P., and Kuhl, D. (2006) Arc/Arg3.1 is essential for the consolidation of synaptic plasticity and memories. Neuron 52, 437-444.

Pozo, K., and Goda, Y. (2010). Unraveling mechanisms of homeostatic synaptic plasticity. Neuron 66 337-351.

Proud, C. G. (2000). "Control of the elongation phase of protein synthesis," in Translational Control of Gene Expression, eds N. Sonenberg, J. Hershy, and M. Mathews (Cold Spring Harbor, NY: Cold Spring Harbor Laboratory Press), 719-739.

Ramirez-Lugo, L., Miranda, M. I., Escobar, M. L., Espinosa, E., and Bermudez-Rattoni, F. (2003). The role of cortical cholinergic preand post-synaptic receptors in taste memory formation. Neurobiol. Learn. Mem. 79, 184-193.

Raught, B., Gingras, A. C., and Sonenberg, N. (2001). The target of rapamycin (TOR) proteins. Proc. Natl. Acad. Sci. U.S.A. 98 7037-7044.

Rodriguez-Duran, L. F., Castillo, D. V., Moguel-Gonzalez, M., and Escobar, M. L. (2011). Conditioned taste aversion modifies persistently the subsequent induction of neocortical long-term potentiation in vivo. Neurobiol. Learn. Mem. 95, 519-526.

Roman, C., Nebieridze, N., Sastre, A., and Reilly, S. (2006). Effects of lesions of the bed nucleus of the stria terminalis, lateral hypothalamus, or insular cortex on conditioned taste aversion and conditioned odor aversion. Behav. Neurosci. 120, 1257-1267.

Roman, C., and Reilly, S. (2007). Effects of insular cortex lesions on conditioned taste aversion and latent inhibition in the rat. Eur. J. Neurosci. 26, 2627-2632.

Rondard, P., Goudet, C., Kniazeff, J., Pin, J. P., and Prezeau, L. (2011). The complexity of their activation mechanism opens new possibilities for the modulation of mGlu and GABAB class C G protein-coupled receptors. Neuropharmacology 60, 82-92.

Rong, Y., Lu, X., Bernard, A., Khrestchatisky, M., and Baudry, M. (2001). Tyrosine phosphorylation of ionotropic glutamate receptors by Fyn or Src differentially modulates their susceptibility to calpain and enhances their binding to spectrin and PSD-95. J. Neurochem. 79, 382-390.

Rosenblum, K. (2008). "Conditioned taste aversion and taste learning: molecular mechanisms," in Concise Learning and Memory: The Editor Selection, ed. J. H. Byrne (Amsterdam: Academic Press, Elsevier), 465-479.

Rosenblum, K., Berman, D. E., Hazvi, S., Lamprecht, R., and Dudai, Y. (1997). NMDA receptor and the tyrosine phosphorylation of its $2 \mathrm{~B}$ subunit in taste learning in the rat insular cortex. J. Neurosci. 17, 5129-5135.

Rosenblum, K., Dudai, Y., and RichterLevin, G. (1996). Long-term potentiation increases tyrosine phosphorylation of the N-methylD-aspartate receptor subunit $2 \mathrm{~B}$ in rat dentate gyrus in vivo. Proc. Natl. Acad. Sci. U.S.A. 93, 10457-10460.

Rosenblum, K., Futter, M., Voss, K., Erent, M., Skehel, P. A., French, P., Obosi, L., Jones, M. W., and Bliss, T. V. (2002). The role of extracellular regulated kinases I/II in late-phase long-term potentiation. J. Neurosci. 22, 5432-5441.

Rosenblum, K., Meiri, N., and Dudai, Y. (1993). Taste memory: the role of protein synthesis in gustatory cortex. Behav. Neural Biol. 59, 49-56.

Rosenblum, K., Schul, R., Meiri, N., Hadari, Y. R., Zick, Y., and Dudai, Y. (1995). Modulation of protein tyrosine phosphorylation in rat insular cortex after conditioned taste aversion training. Proc. Natl. Acad. Sci. U.S.A. 92, 1157-1161.

Ryazanov, A. G., and Davydova, E. K. (1989). Mechanism of elongation factor 2 (EF-2) inactivation upon phosphorylation. Phosphorylated EF-2 is unable to catalyze translocation. FEBS Lett. 251, 187-190.

Sacktor, T. C. (2008). PKMzeta, LTP maintenance, and the dynamic molecular biology of memory storage. Prog. Brain Res. 169, 27-40.

Saddoris, M. P., Holland, P. C., and Gallagher, M. (2009). Associatively learned representations of taste outcomes activate taste-encoding 
neural ensembles in gustatory cortex. J. Neurosci. 29, 15386-15396.

Sajikumar, S., and Korte, M. (2011). Different compartments of apical CA1 dendrites have different plasticity thresholds for expressing synaptic tagging and capture. Learn. Mem. 18, 327-331.

Schachtman, T. R., Bills, C., Ghinescu, R., Murch, K., Serfozo, P., and Simonyi, A. (2003). MPEP, a selective metabotropic glutamate receptor 5 antagonist, attenuates conditioned taste aversion in rats. Behav. Brain Res. 141, 177-182.

Seger, R., and Krebs, E. G. (1995). The MAPK signaling cascade. FASEB J. 9, 726-735.

Seroussi, Y., Brosh, I., and Barkai, E. (2002). Learning-induced reduction in post-burst afterhyperpolarization (AHP) is mediated by activation of PKC. Eur. J. Neurosci. 16, 965-969.

Shema, R., Haramati, S., Ron, S., Hazvi, S., Chen, A., Sacktor, T. C., and Dudai, Y. (2011). Enhancement of consolidated long-term memory by overexpression of protein kinase Mzeta in the neocortex. Science 331, 1207-1210.

Shema, R., Hazvi, S., Sacktor, T. C., and Dudai, Y. (2009). Boundary conditions for the maintenance of memory by PKMzeta in neocortex. Learn. Mem. 16, 122-128.

Shepherd, J. D., and Bear, M. F. (2011). New views of Arc, a master regulator of synaptic plasticity. Nat. Neurosci. 14, 279-284.

Shepherd, J. D., Rumbaugh, G., Wu, J., Chowdhury, S., Plath, N., Kuhl, D., Huganir, R. L., and Worley, P. F. (2006). Arc/Arg3.1 mediates homeostatic synaptic scaling of AMPA receptors. Neuron 52, 475-484.

Simonyi, A., Serfozo, P., Parker, K. E., Ramsey, A. K., and Schachtman, T. R. (2009). Metabotropic glutamate receptor 5 in conditioned taste aversion learning. Neurobiol. Learn. Mem. 92, 460-463.

Simonyi, A., Serfozo, P., Shelat, P. B., Dopheide, M. M., Coulibaly, A. P., and Schachtman, T. R. (2007). Differential roles of hippocampal metabotropic glutamate receptors 1 and 5 in inhibitory avoidance learning. Neurobiol. Learn. Mem. 88, 305-311.

Sjostrom, P. J., Rancz, E. A., Roth, A., and Hausser, M. (2008). Dendritic excitability and synaptic plasticity. Physiol. Rev. 88, 769-840.

St Andre, J., and Reilly, S. (2007). Effects of central and basolateral amygdala lesions on conditioned taste aversion and latent inhibition. Behav. Neurosci. 121, 90-99.

Swank, M. W., and Sweatt, J. D. (2001). Increased histone acetyltransferase and lysine acetyltransferase activity and biphasic activation of the ERK/RSK cascade in insular cortex during novel taste learning. J. Neurosci. 21, 3383-3391.

Sweatt, J. D. (2001). The neuronal MAP kinase cascade: a biochemical signal integration system subserving synaptic plasticity and memory. $J$. Neurochem. 76, 1-10.

Sweetat, S., Rosenblum, K., and Lamprecht, R. (2011). Rho-associated kinase in the gustatory cortex is involved in conditioned taste aversion memory formation but not in memory retrieval or relearning. Neurobiol. Learn. Mem.

Tang, S. J., Reis, G., Kang, H., Gingras, A. C., Sonenberg, N., and Schuman, E. M. (2002). A rapamycin-sensitive signaling pathway contributes to long-term synaptic plasticity in the hippocampus. Proc. Natl. Acad. Sci. U.S.A. 99, 467-472.

Tirosh, S., Elkobi, A., Rosenblum, K., and Meiri, N. (2007). A role for eukaryotic translation initiation factor 2B (eIF2B) in taste memory consolidation and in thermal control establishment during the critical period for sensory development. Dev. Neurobiol. 67, 728-739.

Tsokas, P., Ma, T., Iyengar, R., Landau, E. M., and Blitzer, R. D. (2007). Mitogen-activated protein kinase upregulates the dendritic translation machinery in long-term potentiation by controlling the mammalian target of rapamycin pathway. J. Neurosci. 27, 5885-5894.

Tsui, C. C., Copeland, N. G., Gilbert, D. J., Jenkins, N. A., Barnes, C., and Worley, P. F. (1996). Narp, a novel member of the pentraxin family, promotes neurite outgrowth and is dynamically regulated by neuronal activity. J. Neurosci. 16, 2463-2478.

Tu, J. C., Xiao, B., Naisbitt, S., Yuan, J. P., Petralia, R. S., Brakeman, P., Doan, A., Aakalu, V. K., Lanahan, A. A., Sheng, M., and Worley, P. F. (1999). Coupling of mGluR/Homer and PSD-95 complexes by the Shank family of postsynaptic density proteins. Neuron 23 , 583-592.

Vantaggiato, C., Formentini, I., Bondanza, A., Bonini, C., Naldini, L., and Brambilla, R. (2006). ERK1 and ERK2 mitogen-activated protein kinases affect Ras-dependent cell signaling differentially. J. Biol. 5, 14 .

Vattem, K. M., and Wek, R. C. (2004). Reinitiation involving upstream ORFs regulates ATF4 mRNA translation in mammalian cells. Proc. Natl. Acad. Sci. U.S.A. 101, 11269-11274.

Vlachos, A., Maggio, N., and Jedlicka, P. (2008). Just in time for late-LTP: a mechanism for the role of PKMzeta in long-term memory. Commun Integr. Biol. 1, 190-191.

von Kraus, L. M., Sacktor, T. C., and Francis, J. T. (2010). Erasing sensorimotor memories via PKMzeta inhibition. PLOS ONE 5, e11125. doi:10.1371/journal.pone.0011125

Westmark, P. R., Westmark, C. J., Wang, S., Levenson, J., ORiordan, K. J., Burger, C., and Malter, J. S. (2010). Pin 1 and PKMzeta sequentially control dendritic protein synthesis. Sci. Signal. 3, ra18.

Xiao, B., Tu, J. C., Petralia, R. S. Yuan, J. P., Doan, A., Breder, C. D., Ruggiero, A., Lanahan, A. A., Wenthold, R. J., and Worley, P. F. (1998). Homer regulates the association of group 1 metabotropic glutamate receptors with multivalent complexes of homer-related, synaptic proteins. Neuron 21, 707-716.

Yamamoto, K., Koyanagi, Y., Koshikawa, N., and Kobayashi, M. (2010). Postsynaptic cell type-dependent cholinergic regulation of GABAergic synaptic transmission in rat insular cortex. J. Neurophysiol. 104 1933-1945.

Yamamoto, T., Shimura, T., Sako, N. Yasoshima, Y., and Sakai, N. (1994). Neural substrates for conditioned taste aversion in the rat. Behav. Brain Res. 65, 123-137.

Yamamoto, T., Yuyama, N., Kato, T., and Kawamura, Y. (1984). Gustatory responses of cortical neurons in rats. I. Response characteristics. $J$. Neurophysiol. 51, 616-635.

Yamamoto, T., Yuyama, N., Kato, T., and Kawamura, Y. (1985). Gustatory responses of cortical neurons in rats. III. Neural and behavioral measures compared. J. Neurophysiol. 53, 1370-1386.

Yang, L., Mao, L., Tang, Q., Samdani, S., Liu, Z., and Wang, J. Q. (2004). A novel Ca2+-independent signaling pathway to extracellular signal-regulated protein kinase by coactivation of NMDA receptors and metabotropic glutamate receptor 5 in neurons. J. Neurosci. 24, 10846-10857.
Yasoshima, Y., Morimoto, T., and Yamamoto, T. (2000). Different disruptive effects on the acquisition and expression of conditioned taste aversion by blockades of amygdalar ionotropic and metabotropic glutamatergic receptor subtypes in rats. Brain Res. 869, 15-24.

Yefet, K., Merhav, M., KuulmannVander, S., Elkobi, A., Belelovsky, K., Jacobson-Pick, S., Meiri, N., and Rosenblum, K. (2006). Different signal transduction cascades are activated simultaneously in the rat insular cortex and hippocampus following novel taste learning. Eur. J. Neurosci. 24, 1434-1442.

Ying, S. W., Futter, M., Rosenblum, K., Webber, M. J., Hunt, S. P., Bliss, T. V., and Bramham, C. R. (2002). Brain-derived neurotrophic factor induces long-term potentiation in intact adult hippocampus: requirement for ERK activation coupled to CREB and upregulation of Arc synthesis. J. Neurosci. 22, 1532-1540.

Yu, H., Wang, Y., Pattwell, S., Jing, D., Liu, T., Zhang, Y., Bath, K. G., Lee, F. S., and Chen, Z. Y. (2009). Variant BDNF Val66Met polymorphism affects extinction of conditioned aversive memory. J. Neurosci. 29, 4056-4064.

Zalewska, T., Ziemka-Nalecz, M., and Domanska-Janik, K. (2005). Transient forebrain ischemia effects interaction of Src, FAK, and PYK2 with the NR2B subunit of $\mathrm{N}$ methyl-D-aspartate receptor in gerbil hippocampus. Brain Res. 1042, 214-223.

Conflict of Interest Statement: The authors declare that the research was conducted in the absence of any commercial or financial relationships that could be construed as a potential conflict of interest.

Received: 29 August 2011; accepted: 12 December 2011; published online: 05 January 2012.

Citation: Gal-Ben-Ari $S$ and Rosenblum K (2012) Molecular mechanisms underlying memory consolidation of taste information in the cortex. Front. Behav. Neurosci. 5:87. doi: 10.3389/fnbeh.2011.00087

Copyright (c) 2012 Gal-Ben-Ari and Rosenblum. This is an open-access article distributed under the terms of the Creative Commons Attribution Non Commercial License, which permits noncommercial use, distribution, and reproduction in other forums, provided the original authors and source are credited. 